\title{
Global emissions of fluorinated greenhouse gases 2005-2050 with abatement potentials and costs
}

\author{
Pallav Purohit and Lena Höglund-Isaksson \\ International Institute for Applied Systems Analysis (IIASA), Laxenburg, Austria \\ Correspondence to: Pallav Purohit (purohit@iiasa.ac.at)
}

Received: 11 August 2016 - Discussion started: 16 August 2016

Revised: 31 January 2017 - Accepted: 1 February 2017 - Published: 23 February 2017

\begin{abstract}
This study uses the GAINS model framework to estimate current and future emissions of fluorinated greenhouse gases (F-gases), their abatement potentials, and costs for twenty source sectors and 162 countries and regions, which are aggregated to produce global estimates. Global F-gas (HFCs, PFCs, and $\mathrm{SF}_{6}$ ) emissions are estimated at $0.7 \mathrm{Pg} \mathrm{CO}_{2}$ eq. in 2005 with an expected increase to $3.7 \mathrm{Pg} \mathrm{CO}_{2}$ eq. in 2050 if application of control technology remains at the current level. There are extensive opportunities to reduce emissions using existing technology and alternative substances with low global warming potential. Estimates show that it would be technically feasible to reduce cumulative F-gas emissions from 81 to $11 \mathrm{Pg} \mathrm{CO}_{2}$ eq. between 2018 and 2050. A reduction in cumulative emissions to $23 \mathrm{Pg} \mathrm{CO}_{2}$ eq. is estimated to be possible at a marginal abatement cost below $10 \mathrm{EUR} \mathrm{t}^{-1} \mathrm{CO}_{2}$ eq. We also find that future F-gas abatement is expected to become relatively more costly for developing than developed countries due to differences in the sector contribution to emissions and abatement potentials.
\end{abstract}

\section{Introduction}

Fluorinated greenhouse gases (F-gases) contribute approximately $2 \%$ of the global greenhouse gas emissions (IPCC, 2014). The rapidly increasing demand for refrigeration and cooling services, particularly in developing countries, threatens to increase F-gas emissions considerably over the next few decades. Many F-gases have very high global warming potentials (GWPs) and therefore small atmospheric concentrations can have large effects on global temperatures. In this work, we identify and quantify all important sources of F- gas emissions at a global scale, the potential for reducing emissions, and the associated abatement costs. A baseline scenario for future F-gas emissions is developed, taking account of future emission control expected from national and international legislations adopted before July 2016 when this paper was first submitted. Hence, the baseline scenario does not account for the effects of the amended Montreal Protocol agreed in Kigali, Rwanda, in October 2016. Using the framework of the Greenhouse gas and Air pollution Interactions and Synergies (GAINS) model (http://gains.iiasa.ac.at), we estimate in 5-year intervals for 2005 to 2050 global emissions and abatement potentials of the F-gases (hydrofluorocarbons (HFCs), perfluorocarbons (PFCs) and sulfur hexafluoride $\left.\left(\mathrm{SF}_{6}\right)\right)$, which are addressed under the Kyoto Protocol (KP) (UNFCCC, 2014). To account for the full global warming effect of the combined use of HFCs and hydrochlorofluorocarbons (HCFCs) as coolants, and considering that they are close substitutes with equally strong GWPs, we keep track of and display baseline HCFC emissions in parallel to HFC emissions, even though HCFCs are not a target for future abatement efforts since they are addressed as ozonedepleting substances (ODSs) that are subject to phase-out under the Montreal Protocol (MP) (UNEP, 2007). Twenty source sectors (14 for HFCs, 2 for PFCs and 4 for $\mathrm{SF}_{6}$ emissions) are identified and emissions are estimated separately for 162 countries and regions. For each F-gas source sector, we identify a set of abatement options and estimate their reduction potentials and costs based on information from publicly available sources. We also point out major sources of uncertainty and highlight critical gaps in knowledge.

Our work adds to existing literature (Velders et al., 2009; Gschrey et al., 2011; Meinshausen et al., 2011; Montzka et al., 2011; USEPA, 2013; Velders et al., 2014; Ragnauth et al., 
2015; Velders et al., 2015) an independently developed emission inventory with future projections and abatement potentials estimated at the technology level, thereby allowing for a high degree of resolution for the estimated emissions, abatement potentials and marginal abatement cost curves.

Our findings confirm previous findings (EDGAR, 2013; Gschrey et al., 2011; Velders et al., 2009) that in 2005 emissions of HFCs, PFCs, and $\mathrm{SF}_{6}$ contributed about $0.7 \mathrm{Pg} \mathrm{CO}_{2}$ eq. to global greenhouse gas emissions, while our baseline projection, reaching $3.7 \mathrm{Pg} \mathrm{CO}_{2}$ eq. in 2050 , is somewhat lower than the business-as-usual estimates of previous studies (Velders et al., 2015; Gschrey et al., 2011), as discussed further in Sect. 4.5.

Section 2 presents the methodology used to estimate emissions and abatement costs. Section 3 describes the development of emission scenarios. Section 4 presents results with comparisons to previous studies. Section 5 discusses different sources of uncertainty and Sect. 6 concludes the study. More details on HFCs, PFCs, and $\mathrm{SF}_{6}$ consumption as well as emission estimation and abatement potentials and costs are provided in Sect. S2 of the Supplement.

\section{Methodology}

\subsection{F-gas emission estimation in GAINS}

The estimation of current and future F-gas emissions and the potential for emission reductions and costs follow standard GAINS model methodology (Amann et al., 2011) with some modifications specific to F-gases. To account for the wide spread in global warming potentials for different Fgases, emission factors are converted to carbon dioxide $\left(\mathrm{CO}_{2}\right)$ equivalents by multiplying the technology-specific emission factor with the respective GWPs over 100 years (IPCC, 2007a). Starting from April 2015, Annex-I (industrialized) countries report all greenhouse gases to the United Nations Framework Convention on Climate Change (UNFCCC) (UNFCCC, 2015a) using GWPs from IPCC AR4 (IPCC, 2007b). As the official reporting to UNFCCC functions as a basis for negotiations of future climate policy proposals, we apply IPCC AR4 GWPs throughout this analysis, however, make comparisons to the use of IPCC AR2 (IPCC, 1996) and IPCC AR5 (IPCC, 2014) GWPs in the uncertainty analysis in Sect. 4. A complete list of GWPs for different substances recommended under the second, fourth, and fifth IPCC ARs are presented in Table S2 of the Supplement.

For each pollutant (i.e., HFC, $\mathrm{PFC}$, and $\mathrm{SF}_{6}$ ), the GAINS model estimates current and future emissions based on activity data, uncontrolled emission factors, the removal efficiency of emission control measures and the extent to which such measures are applied, as follows:

$$
E_{i, p}=\sum_{k} \sum_{m} A_{i, k} \mathrm{ef}_{i, k, m, p} \mathrm{GWP}_{i, k, p} X_{i, k, m, p}
$$

where $i, k, m$, and $p$ represent the country, activity type, abatement technology, and pollutant, respectively, $E_{i, p}$ indicates emissions of specific pollutant $p$ (i.e., here HFC, PFC, and $\mathrm{SF}_{6}$ ) in country $i, A_{i, k}$ is the activity level of type $k$ in country $i, \mathrm{ef}_{i, k, m, p}$ is the emission factor of pollutant $p$ for activity $k$ in country $i$ after application of control measure $m, \mathrm{GWP}_{i, k, p}$ is the global warming potential of pollutant $p$ when applied in country $i$ to sector $k$, and $X_{i, k, m, p}$ is the share of total activity of type $k$ in country $i$ to which control measure $m$ for pollutant $p$ is applied.

Structural differences in emission sources are reflected through country-specific activity levels. Major differences in the emission characteristics of specific sources are represented through source-specific emission factors, which account for the extent to which emission control measures are applied. The GAINS model estimates future emissions by varying activity levels along exogenous projections of the development of human activity drivers and by adjusting implementation rates of emission control measures (e.g., HöglundIsaksson et al., 2012). In a further step, uncontrolled emission factors and removal efficiencies for given control measures are summarized in adjusted emission factors. This approach allows for the capture of critical differences across economic sectors and countries that might justify differentiated emission reduction strategies on the basis of cost-effectiveness.

\subsection{Activity data}

Activity data used to estimate HFC emissions in the years 2005 and 2010 is derived from HFC consumption reported by Annex-I countries to the UNFCCC (UNFCCC, 2012). For non-Annex-I countries (i.e., primarily developing countries), HCFC and HFC consumption data is extracted from available literature (MoEF, 2009; UNEP, 2011a; GIZ, 2014; UNDP, 2014a, b). However, for some non-Annex-I countries very limited information is available on the HFC use, which prompts the use of default assumptions, adding to uncertainty in the estimates for these countries. For HFC use in refrigeration, air conditioning, fire extinguishers, and ground-source heat pumps, HFC emissions are estimated separately for "banked" emissions, i.e., leakage from equipment in use, and for "scrapping" emissions, i.e., emissions released at the end-of-life of the equipment. This is also the format used by countries when reporting HFC emissions to the UNFCCC (2015a). As domestic refrigerators are hermetic there is no risk of leakage during use and therefore only "scrapping" emissions are accounted for. At the end-oflife, the scrapped equipment is assumed to be fully loaded with refrigerant which needs recovery, recycling, or destruction. In addition, for each HFC emission source, the fraction of HCFC in the HFC/HCFC use is identified from reported baselines ${ }^{1}$ of parties to the MP and modeled in consistency

$\begin{array}{lll}{ }^{1} 1989 \text { HCFC } & \text { consumption } \\ 1989 \quad \text { consumption for non-Article } & 2.8 \% \text { of }\end{array}$
Average of 2009 and 2010 for Article 5 countries 
with the phase-out schedule of HCFCs in the latest revision of the MP (UNEP, 2007) and including later baseline updates reported by the parties to the UNEP Ozone Secretariat and in the HCFC Phase-out Management Plans (HPMPs) (GEF, 2009; MoEF, 2009; UNEP, 2011a; PU, 2012; UNDP, 2012; MoEF, 2013; Yong, 2013; GIZ, 2014; UNDP, 2014a, $\mathrm{b}$; UNEP, 2014a, b). These sources provide information on how much HCFC can be used by a given country in a given year - and the rest of the baseline demand is assumed to be met through HFCs. Drivers for projections of HFC use differ by sector and are consistent with the macroeconomic and energy sector developments described by the Reference scenario of the IEA's Energy Technology Perspectives 2012 (IEA/OECD, 2012) for non-EU countries and with the Reference scenario of the PRIMES model (Capros et al., 2013) for EU countries. Depending on the sector, different drivers have been used to derive future HFC emissions. For example, the use of HFC-134a in mobile air conditioners is driven by a projection of the vehicle numbers taken from the GAINS model and consistent with the future development in vehicle fuel use by IEA/OECD (2012) and Capros et al. (2013). A driver for HFCs used in commercial and industrial refrigeration is the projection of value added for commercial and industry sectors, respectively. A complete list of HFC drivers with references is presented in Table S5 of the Supplement. Figure 1 shows the future development in major drivers for F-gas emissions on a global scale between $2005(=100)$ and 2050 as they follow from IEA/OECD (2012) and Capros et al. (2013).

To the extent that information is available from public sources, country-specific data have been collected for the most important industry source sectors, i.e., the production of difluorochloromethane (HCFC-22), primary aluminium, and magnesium. Activity data for 2005 and 2010 production of primary aluminium and magnesium are taken from the US Geological Survey (USGS, 2013a, b), except for the EU countries for which the source is the PRIMES model (Capros et al., 2013), and for China and India for which primary aluminium production data is obtained from the GAINS Asia project (Amann et al., 2008; Purohit et al., 2010). Although HFC-23 is primarily generated as a by-product of HCFC22 production for use as industry feedstock or emissive use (the latter to be phased out under the MP), it is also used directly in fire protection and integrated circuits or semiconductor industry. A small share of HFC-23 is also reported by parties to be used in commercial and industrial refrigeration sectors (UNFCCC, 2012). Production levels are reported for historical years (UNEP, 2014c) and with fractions of production for feedstock and emissive use, respectively, taken from IPCC/TEAP (2005). Projections of future production in these industries are assumed to follow growth in industry value added (IEA/OECD, 2012; Capros et al., 2013).

\subsection{Emission factors}

Sector-specific leakage rates are taken from various published sources (Harnisch and Schwarz, 2003; IPCC/TEAP, 2005; Tohka, 2005; Garg et al., 2006; Schwarz et al., 2011; UNFCCC, 2012; Höglund-Isaksson et al., 2012, 2013, 2016) and typically differ between industrialized (Annex-I) and developing (non-Annex-I) countries (Gschrey et al., 2011).

To convert emission factors to $\mathrm{CO}_{2}$-equivalent terms, these have been multiplied with sector-specific GWPs. The GWPs of HFCs replacing ODSs ranges from 124 (HFC-152a) to 14800 (HFC-23) (IPCC, 2007b) over 100 years and with different HFCs used to different extents in different sectors. To weigh the sector-specific GWPs by the shares of different types of HFCs commonly used in the respective sectors, we combine sector-level information provided by Gschrey et al. (2011) with country-specific information provided by Annex-I countries in the common reporting format to the UNFCCC (UNFCCC, 2012). The sector-specific GWPs are presented in Table S2 of the Supplement.

Primary aluminium production, semiconductor manufacturing, and flat panel display manufacturing are the largest known sources of tetrafluoromethane $\left(\mathrm{CF}_{4}\right)$ and hexafluoroethane $\left(\mathrm{C}_{2} \mathrm{~F}_{6}\right)$ emissions. PFCs are also relatively minor substitutes for ODSs. Over a 100-year period, $\mathrm{CF}_{4}$ and $\mathrm{C}_{2} \mathrm{~F}_{6}$ are, respectively, 7390 and 12200 times more effective than $\mathrm{CO}_{2}$ at trapping heat in the atmosphere (IPCC, 2007b). The International Aluminium Institute (IAI) observed a median emission factor for point feed prebake (PFPB) technology for eight Chinese smelters that is 2.6 times larger than the global PFPB technology average (IAI, 2009). Assuming the Chinese emissions factor is constant over time (Mühle et al., 2010), the revised PFC emissions factor for Chinese aluminium smelters of 0.7 tonne $\mathrm{CO}_{2}$ eq. per tonne of $\mathrm{Al}$ produced is used in this study, while the global PFPB technology average of 0.27 tonne $\mathrm{CO}_{2}$ eq. per tonne of $\mathrm{Al}$ produced is used for other countries and regions.

The GWP of $\mathrm{SF}_{6}$ is 22800 , making it the most potent greenhouse gas evaluated by IPCC (IPCC, 2007b). It is used (a) for insulation and current interruption in electric power transmission and distribution equipment, (b) to protect molten magnesium from oxidation and potentially violent burning in the magnesium industry, (c) to create circuitry patterns and to clean vapor deposition chambers during manufacture of semiconductors and flat panel displays, and (d) for a variety of smaller uses, including uses as a tracer gas and as a filler for sound-insulated windows (USEPA, 2013). For the case of magnesium processing, $\mathrm{SF}_{6}$ consumption factors of $1.65 \mathrm{~kg} \mathrm{SF}_{6}$ per tonne of $\mathrm{Mg}$ is used for China (Fang et al., 2013) and a default value (1.0 $\mathrm{kg} \mathrm{SF}_{6}$ per tonne of $\mathrm{Mg}$ ) suggested by the IPCC (IPCC, 2006) is used for other regions. 

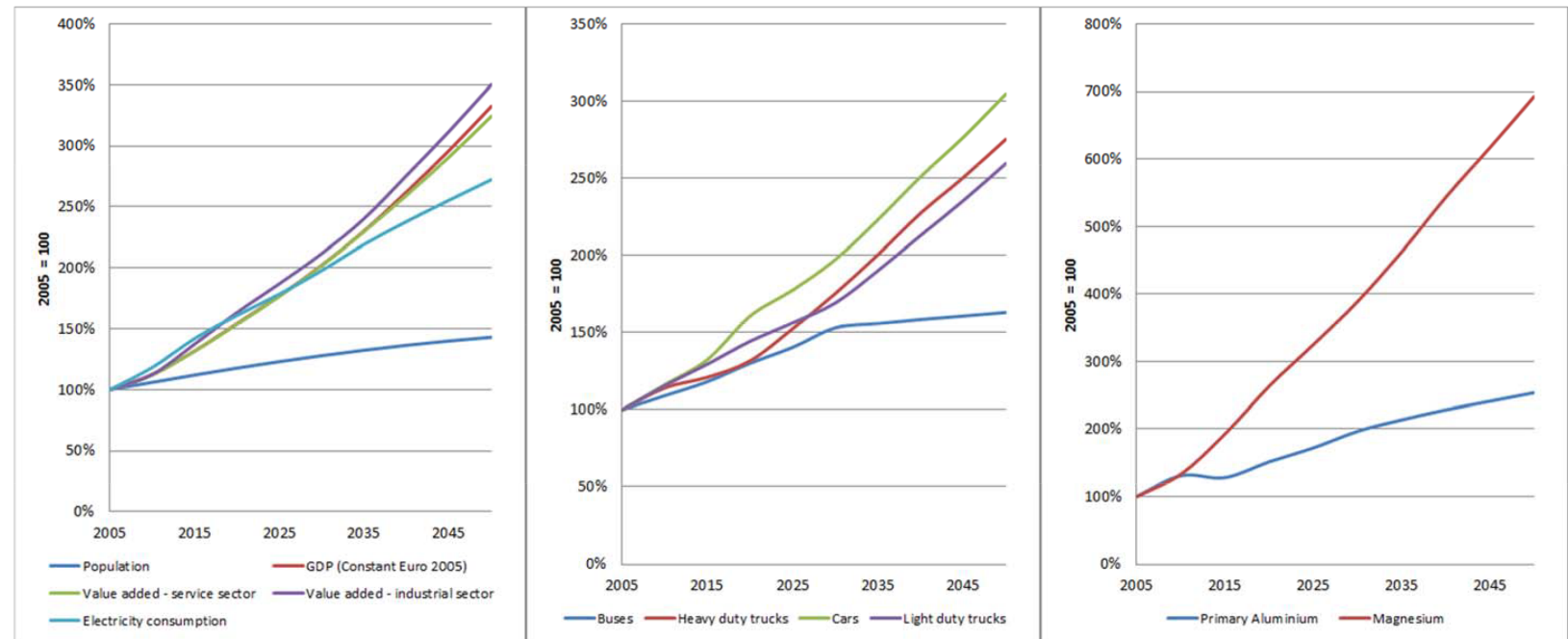

Figure 1. Global development 2005-2050 in major drivers for F-gas emissions entering model estimations from external sources Source: (IEA/OECD, 2012; Capros et al., 2013; USGS, 2013a-b).

\subsection{Abatement costs}

F-gas abatement costs per unit of activity in GAINS have been calculated as the sum of investment costs, non-energy operation and maintenance costs and energy-related costs (or savings). The unit cost of technology $m$ in country/region $i$ and year $t$ is defined as follows:

$C_{i t m}=I_{i m}\left[\frac{(1+r)^{T} \times r}{(1+r)^{T}-1}\right]+M_{i m}+\left(E_{i m} \times p_{i t}^{\text {electr }},\right)$

where $I_{i m}\left[\frac{(1+r)^{T} \times r}{(1+r)^{T}-1}\right]$ represents the annualized investment cost for technology $m$ in country $i$ and with interest rate $r$ and technology lifetime of $T$ years, $M_{i m}$ is the non-energy related annual operation and maintenance cost for technology $m, E_{i m}$ is the demand for electricity, and the electricity price is in country $i$ in year $t$.

The price of electricity is assumed to be linked to the gas price in the following way (Höglund-Isaksson et al., 2013):

$p_{i t}^{\text {electr }}=3+2 p_{i t}^{\text {gas }}$.

The expected trajectory of future gas prices through 2030 follows IEA/OECD (2012) for non-EU countries and Capros et al. (2013) for EU countries.

The marginal cost per unit of reduced emissions is defined for each technology available to a sector as the unit cost divided by the difference between the technology emission factor and the no control emission factor:

$\mathrm{MC}_{i t m}^{\mathrm{Tech}}=\frac{C_{i t m}}{\mathrm{ef}_{i t}^{\text {No_control }}-\mathrm{ef}_{i t m}}$,

where $\mathrm{ef}_{i t}^{\mathrm{No} \_ \text {control }}$ is the no control emission factor and $\mathrm{ef}_{i t m}$ is the emission factor after abatement control has been implemented.
We refer to this as the "technology marginal cost". Within a sector, the technologies available are first sorted by their respective technology marginal cost. The technology with the lowest technology marginal cost is ranked the first-best technology and assumed to be adopted to its full extent in a given sector. The second-best technology is the technology with the second lowest technology marginal cost and is assumed to be available for adoption provided it can achieve an emission factor that is lower than the first-best technology. The marginal cost of the second-best technology when implemented in the marginal cost curve is defined as follows:

$\mathrm{MC}_{i t 2}=\frac{C_{i t 2}-C_{i t 1}}{\mathrm{ef}_{i t 1}-\mathrm{ef}_{i t 2}}$.

Hence, the marginal abatement cost curve displays the relationship between the cost of reducing one additional emission unit and the associated emission control potential.

Note that abatement costs are defined as the incremental cost of switching from the current technology to an enhanced technology in terms of greenhouse gas emissions. Many alternative technologies provide additional indirect emissions savings and monetary benefits through increased energy efficiency, as compared to traditional HFC technologies (Kauffeld, 2012; Zaelke and Borgford-Parnell, 2015; UNEP, 2016a). We have included monetary benefits accrued by increased energy efficiency. Some alternative substances are known to be flammable and/or toxic and may need special precaution in handling and training of staff. For such substances to be considered feasible, we limit our options to substances that are known to already have wide application in a given sector. Transaction costs, e.g., the one-time cost of training staff in the use of a different substances and introduction of new safety routines, are not considered in the abatement cost. For example, switching from high-GWP HFCs to 
ammonia $\left(\mathrm{NH}_{3}\right)$ in industrial refrigeration will initially require special attention to be paid to the handling as $\mathrm{NH}_{3}$ is toxic and has flammable properties (UNEP and SEPA, 2010, p. 25). Another important consideration for $\mathrm{NH}_{3}$ is its propensity for corrosion and its affinity for moisture (UNEP, 2015 , p. 46). On the other hand, $\mathrm{NH}_{3}$ is, and has for decades been, widely used in industrial refrigeration, which proves that its toxicity and flammability is not an unsurmountable obstacle for adoption. Hence, the abatement cost for switching to $\mathrm{NH}_{3}$ in industrial refrigeration is measured as the difference in costs between HFCs and $\mathrm{NH}_{3}$ per cooling unit, where the latter is less expensive and also more energy efficient, thereby rendering a negative net cost for the option (see Tables S6-S7 in the Supplement for more details on input parameters for costs).

\subsection{Geographic coverage of F-gas in GAINS}

Geographic coverage of F-gas emission estimates in the GAINS model is global, with the world divided into 162 regions. Emissions, abatement potentials, and costs are calculated for each region; however for display purposes these are aggregated into 14 world regions, as shown in Table S8 of the Supplement.

\section{Development of F-gas emission scenarios}

\subsection{Baseline scenario}

To estimate F-gas emissions in the baseline scenario, we take into account the effects on emissions from implementation of existing legislation to control F-gas emissions at the regional or national level as stated in publicly available information and summarized in Table 1. Further details on the intention, stringency, and targets of the existing F-gas legislations are presented in Table S9 of the Supplement.

The first EU-wide F-gas regulation (EC 842/2006) was implemented in 2006 to control the release of F-gases from stationary cooling and refrigeration equipment. The regulation also requires an increased use of alternative blowing agents for one-component foams, use of alternative propellants for aerosols, leakage control and end-of-life recollection and recycling of high- and mid-voltage switches, $\mathrm{SF}_{6}$ replaced by $\mathrm{SO}_{2}$ in magnesium production and casting, and a ban on the use of $\mathrm{SF}_{6}$ in soundproof windows, sports equipment, etc. The EU mobile (or motor vehicle) air-conditioning (MAC) directive (2006/40/EC) bans the use of HFC-134a in mobile air conditioners from 2017. In 2014, a revised EU F-gas regulation (EC 517/2014) was adopted which places bans on the use of high-GWP HFCs in refrigeration, air conditioning and a few other sectors starting from January 2015 and also containing a phase-down of HFC consumption from a base level. By 2030, the new regulation is expected to cut the EU's F-gas emissions by two-thirds compared to the 2014 level (Capros et al., 2016). Following the requirements of the amendment
(EC/29/2009) of the EU ETS Directive, PFC emissions from the primary aluminium industry are included in the EU ETS emission cap. In addition to EU-wide F-gas legislation, there is comprehensive national legislation in place targeting $\mathrm{F}$ gas emissions in Austria, Belgium, Denmark, Germany, the Netherlands, and Sweden. These regulations were typically put in place prior to the EU-wide legislation and are more stringent and address more specific sources than the EU-wide regulation.

Apart from the EU, Japan, the USA, Australia, Norway, and Switzerland have also implemented national regulations to limit the use of high-GWP HFCs. These are all non-Article 5 countries under the MP and have introduced HFCs several years ago as a mean to replace CFCs and HCFCs under the ODS phase-out schedule. The approaches chosen comprise different regulatory measures including the use of marketbased instruments such as taxes (Schwarz et al., 2011). In the United States, there are economic incentives in place to eliminate HFCs for use in mobile air-conditioners (USEPA, 2012) and recent regulations (USEPA, 2015) are expected to further limit the use of high-GWP HFCs. Similar new regulations are in place in Japan (METI, 2015). Switzerland banned HFCs in a series of air conditioning and refrigeration applications from December 2013 (UNEP, 2014d). In Australia, as part of the clean energy future plan, synthetic greenhouse gas (SGG) refrigerants have attracted an "equivalent carbon price" based on their global warming potentials since 1 July 2012 (AIRAH, 2012). Note that the phase-down of the global use of HFCs agreed in the Kigali Amendment to the Montreal Protocol during the 28th Meeting of the Parties in October 2016 (UNEP, 2016b), was not available at the submission date of this paper and has therefore not been considered in the baseline analyzed here. Its implications for emissions and costs will be the focus of a separate analysis.

Due to the relatively high cost of HFO-1234yf compared to HFC-134a (Schwarz et al., 2011; Carvalho et al., 2014; USEPA, 2013; Purohit et al., 2016) and extensive import bans and restrictions on international trade with used cars (UNEP, 2011b; Macias et al., 2013), we consider it unlikely that new MAC technology will be taken up in the absence of directed regulations or spread globally through export of used cars from regions with regulations in place.

HFC-23 emissions from HCFC-22 production are assumed to be fully equipped with post-combustion technology in OECD countries. The USEPA (2006) and UNEP (2007) project, until 2050, a shift of most HCFC-22 production from OECD countries to China and other developing countries. Note that this refers to the production of HCFC-22 for feedstock use in industry, which is not required to be phased out under the MP. Several studies (e.g., Wara, 2007; Miller et al., 2010; Miller and Kuijpers, 2011; Montzka et al., 2010) discuss the impact of the Clean Development Mechanism 


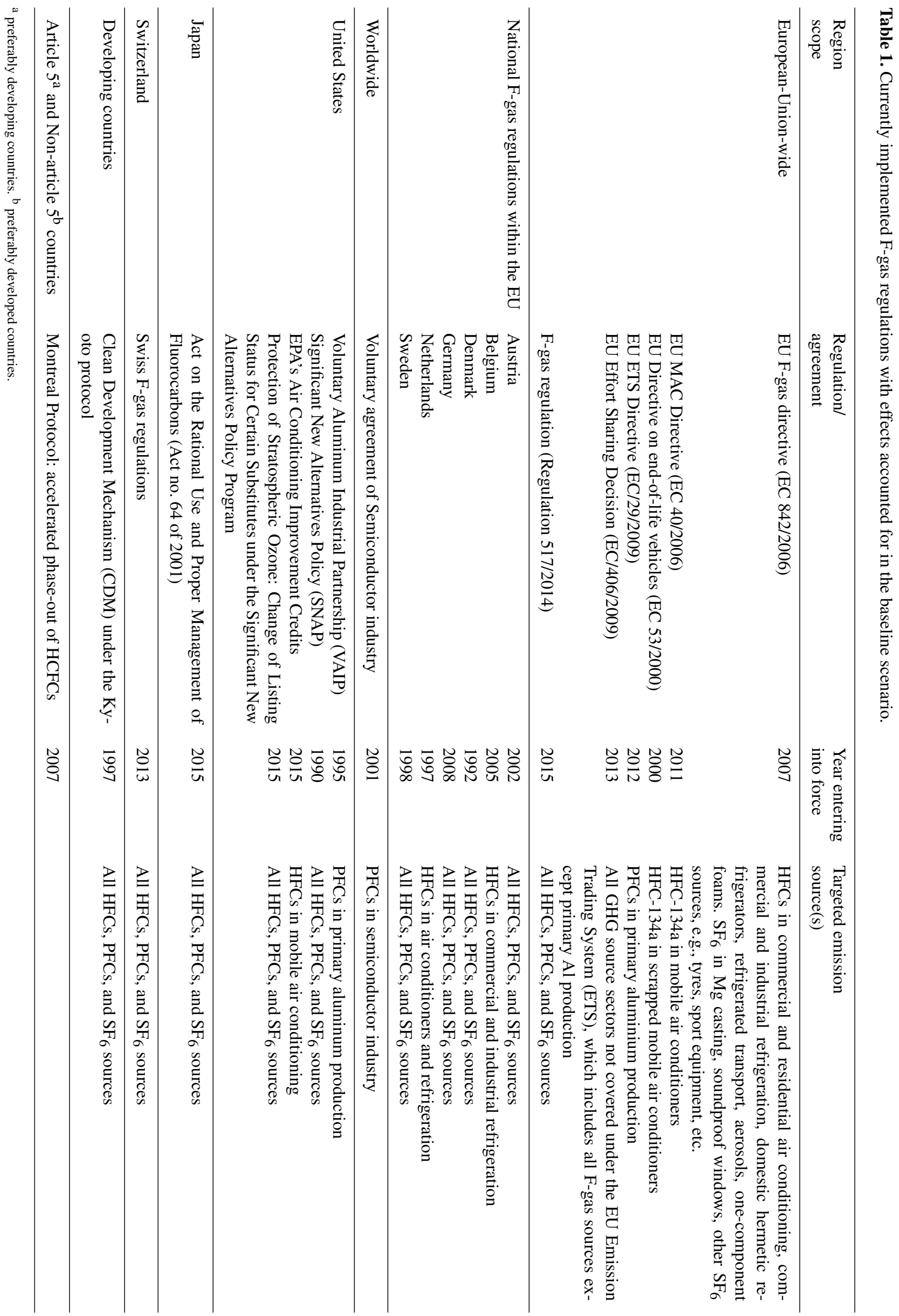


$(\mathrm{CDM})^{2}$ projects on global HFC-23 emissions for this sector. HFC-23 emissions from HCFC-22 production are assumed to be controlled in most developing countries due to $\mathrm{CDM}$, except China where $36 \%$ of HCFC-22 production is controlled (Feng et al., 2012). According to the investment plan to support destruction of HFC-23 issued by the Chinese National Development and Reform Commission (NDRC) 2015, the Chinese government plans to introduce subsidies, per tonne of $\mathrm{CO}_{2}$ eq., for the implementation of new HFC-23 destruction devices for HCFC-22 production plants that are already in operation without support from the CDM (NDRC, 2015; Schneider et al., 2015; Munnings et al., 2016). According to personal information from Z. Zhai (College of Environmental Sciences and Engineering, Peking University, Beijing, personal communication, 19 October 2016), a current subsidy per tonne of $\mathrm{CO}_{2}$ equivalent removed is RMB 4, $3.5,3,2.5,2$, and 1 in the years 2014 to 2019, respectively. The subsidy will end in 2020 . Therefore, the enterprises are already encouraged to report data about production and destruction amounts and new facility plans. Together with the other mentioned regulations, we consider the existence of this incentive scheme an indication that the Chinese government is interested in continued control of emissions from this source after 2020 when the subsidy is phased out. The Intended Nationally Determined Contributions (INDCs) submitted by China to the UNFCCC (UNFCCC, 2015b) in preparation of the Paris Agreement (UNFCCC, 2015c) also aims to phase down use of HCFC-22 and to "achieve effective control" of HFC-23. Due to difficulties in assessing the overall impact of the above-mentioned Chinese policies to control HFC-23 emissions from HCFC-22 production, we make a general assumption in the baseline scenario that the current control level of $36 \%$ will at least not decline and will stay constant into the future. Moreover, India announced during the 28th Meeting of the Open-Ended Working Group (OEWG 38) of the parties to the Montreal Protocol that its chemical industry, with immediate effect, must collect and destroy emissions of HFC-23 (Mahapatra, 2016). Therefore, we assume in this analysis that the impact of CDM on emissions from HCFC-22 production in developing countries also remains at the current level in the future.

In non-Annex-I countries, China has developed HFC phase-down programs, including (i) capacity-building; (ii) collection and reporting of HFC emissions data; (iii) mobilization of financial resources for further actions to phase down HFCs; (iv) research, development, and deployment of environmentally sound, effective, and safe alternatives and

\footnotetext{
${ }^{2}$ The Clean Development Mechanism (CDM) is one of the flexible mechanisms defined in the Kyoto Protocol that allows emissionreduction projects in non-Annex-I (developing) countries to earn certified emission reduction (CER) credits, each equivalent to $1 \mathrm{t}$ of $\mathrm{CO}_{2}$. These CERs can be traded and sold, and used by Annex-I (industrialized) countries to a meet a part of their emission reduction targets under the Kyoto Protocol.
}

technologies; and (v) multilateral agreements to phase down HFCs (Fekete et al., 2015). Belize, Burkina Faso, Colombia, Egypt, and Paraguay require import licenses for HFCs (Brack, 2015). It is, however, unclear if these have had a negative effect on the use of HFCs and we therefore do not account for them in the baseline. Turkey is planning to strengthen legislation on ozone-depletion and fluorinated gases (UNEP, 2013); however, effects of planned policies are not included in the baseline. Paraguay and the Seychelles have implemented fiscal incentives including taxes and subsidies to encourage a switch from HFCs and HCFCs to alternative low-GWP substitutes (Brack, 2015). These two countries are modeled in GAINS as part of larger regions ("Other Latin America" and "Other Africa") and we are therefore not able to reflect the effect of these national legislations in the baseline.

The general trend in the aluminium industry is switching from existing Horizontal Stud Söderberg (HSS), Vertical Stud Söderberg (VSS), or prebake technologies to PFPB technology. According to the 2013 Anode Effect Survey of the International Aluminium Institute (IAI, 2014), PFC emission intensity (as $\mathrm{CO}_{2}$ eq. per tonne of production) from the global aluminium industry has been reduced by more than 35\% since 2006 and by almost 90\% since 1990. With primary aluminium production having grown by over $150 \%$ over the same period, absolute emissions of PFCs from the industry have been reduced from approximately $100 \mathrm{Tg} \mathrm{CO}_{2}$ eq. in 1990 to $32 \mathrm{Tg} \mathrm{CO}_{2}$ eq. in 2013 (IAI, 2014). In EU-28, emissions from primary aluminium production are regulated under the EU ETS system. As the marginal cost of a switch to PFPB technology falls below the expected ETS carbon price, the baseline assumption is that with the natural turnover of capital, all EU member states will have phased in PFPB technology by 2020 (Höglund-Isaksson et al., 2016). Primary aluminium production in China is estimated at $55 \%$ of the global production capacity of $58.3 \mathrm{Mt}$ in 2015 (USGS, 2016) and with almost all production facilities employing PFPB technology (Hao et al., 2016). For other non-EU regions, current technology used in primary aluminium smelters is, in the baseline, assumed to remain until 2050.

There is a voluntary agreement in place among semiconductor producers worldwide to reduce PFC emissions to $10 \%$ below the 1995 level by 2010 (Huang, 2008). According to industry (WSC, 2016), over a 10-year period the semiconductor industry achieved a $32 \%$ reduction in PFC emissions, surpassing its voluntary commitment. Since 2010, the industry has set a new goal based on a normalized (i.e., relative to production levels) target instead of an absolute target and has established best practices for new manufacturing capacity that will continue to improve efficiency (WSC, 2016). Since PFC is only used by a few companies in a country (Tohka, 2005) and as the amount of PFC used allows for the derivation of the production volumes, data on PFC use is often confidential. Therefore GAINS uses PFC emissions 
reported to UNFCCC (2012) as activity data for this sector. Further information is provided in Sect. S2.2 of the Supplement.

Finally, the baseline assumes full implementation of the accelerated HCFC phase-out schedule agreed to by the MP Parties in September 2007 (UNEP, 2007). The HCFC phaseout in non-Article 5 (mainly developed) countries will have achieved a $90 \%$ reduction by 2015 , but since climate cobenefits were not a condition or aspiration of the MP, transitions did not favor low-GWP alternatives, even where such had been developed and commercialized (EIA, 2012). Under the accelerated schedule, HCFC consumption in Article5 (developing) countries will be frozen in 2013 at the average production levels of 2009 and 2010. More prominently, the Parties agreed to cut HCFC production and consumption in developing countries by $10 \%$ by $2015,35 \%$ by 2020 and $67.5 \%$ by 2025 , with the phase-out virtually completed in 2030. For each emission source, the fraction of HCFCs to HFCs in use is identified as per the latest information and is modeled in GAINS following the accelerated phase-out schedule of HCFCs under the MP.

\subsection{Maximum technically feasible reduction scenario}

In the maximum technically feasible reduction (MFR) scenario, the abatement potential encompasses reductions in emissions through the application of technologies that are currently commercially available and already tested and implemented, at least to a limited extent. Table S6 of the Supplement presents abatement options for HFC emissions in GAINS and provides references to literature. HFC control options fall into four broad categories:

a. Good practice: this encompasses a package of measures including improved components, leak prevention during use and refill, maintenance and end of life recovery, and recollection of refrigerants. The removal efficiency is 20 to $50 \%$ for the emissions banked in refrigeration and air-conditioning equipment and 80 to $88 \%$ for the emissions from scrapped equipment (Tohka, 2005; HöglundIsaksson et al., 2013, 2016).

b. Switching to low-GWP HFCs: HFCs currently in use have relatively long atmospheric lifetimes -15 years on average - which makes GWPs relatively high, ranging from 1430 to 14800 times that of $\mathrm{CO}_{2}$ over 100 years (IPCC, 2007b). Alternative HFCs offer shorter lifetimes and considerably lower GWPs, e.g., HFC-152a has a GWP of 124 and HFC-32 has a GWP of 675 (IPCC, 2007b). Moreover, use of HFC-32 in air conditioning and heat pumps can improve energy efficiency by 5 to $10 \%$ depending on the model (Daikin, 2016). For air conditioning, removal efficiency when switching to HFC-32 is taken to be $68 \%$ for room air conditioners. Similarly, removal efficiency when switching to HFC$152 \mathrm{a}$ is taken to exceed $90 \%$ in foam, non-medical aerosol, and other applications (see Table S6 of the Supplement for references).

c. Switching to new cooling agents: in recent years, alternative substances with very short lifetimes of less than a few months have been developed and marketed, e.g., HFO-1234ze with a GWP of 6 for use in aerosols and foam products and HFO-1234yf with a GWP of 4 for mobile air-conditioners. The removal efficiency of new cooling agents exceeds $99 \%$ for mobile air conditioning and aerosol or foam sectors (see Table S6 of the Supplement for references).

d. Other non-HFC substances with low or zero GWPs: commercial examples include hydrocarbons (e.g., R290), $\mathrm{NH}_{3}, \mathrm{CO}_{2}$, dimethyl ether, and a diversity of other substances used in foam products, refrigeration, air-conditioning, and fire protection systems. Switching involves process modifications, e.g., changing the process type from ordinary to secondary loop systems (Halkos, 2010). Industrial ammonia systems are in general $15 \%$ more energy efficient than their HFC counterparts (Schwarz et al., 2011).

HFC-23 (GWP100 $=14800)$ is an unwanted waste gas from the production of HCFC-22. HFC-23 can be abated through process optimization combined with thermal oxidation of the gas through incineration. The HFC-23/HCFC-22 ratio is typically in the range between 1.5 and $4 \%$ (Schneider, 2011), depending on how the process is operated and the degree of process optimization that has been performed (McCulloch and Lindley, 2007), but can technically be reduced below $1 \%$ (IPCC/TEAP, 2005). The removal efficiency of incineration of HFC-23 is taken to be virtually complete $(99.99 \%$ ) (World Bank, 2010).

In GAINS, four current production technologies for primary aluminium are considered: side-worked prebake (SWPB), centre-worked prebake (CWPB), vertical stud Söderberg (VSS), and point feed prebake (PFPB). The identified PFC control options include retrofitting plants with existing technologies or converting the plants to PFPB technology. Inert anode technology for aluminium smelters with $100 \%$ removal efficiency is, in GAINS, assumed to be available as an abatement option from 2035 onwards (IEA/OECD, 2010). Table S7 of the Supplement lists the abatement measures for PFC emissions in the primary aluminium production and semiconductor manufacture sectors and provide references to literature. The removal efficiency of conversion of existing primary aluminium production technologies (VSS, SWPB and CWPB) to PFPB technology is more than $85 \%$ whereas retrofitting has a removal efficiency of about $26 \%$ (Harnisch et al., 1998; Harnisch and Hendriks, 2000).

The GAINS model considers three control options for reducing $\mathrm{SF}_{6}$ emissions: (a) good practice, which for high and mid-voltage electrical switchgears (HMVES) includes leak- 


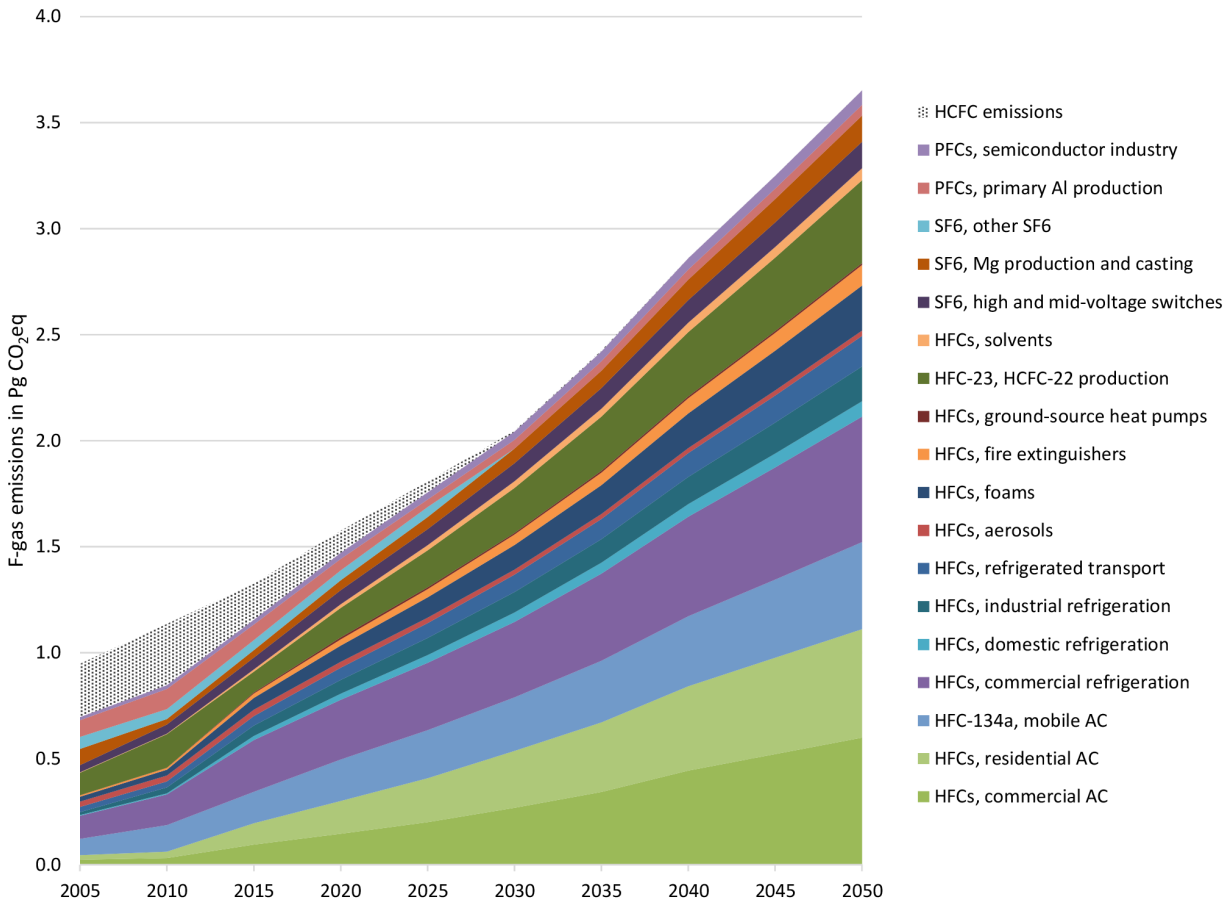

Figure 2. Baseline emissions of F-gases (HFCs, PFCs, and $\mathrm{SF}_{6}$ ) 2005 to 2050 by source sector. To facilitate comparison to other studies only reporting HFCs, PFCs, and $\mathrm{SF}_{6}$, the HCFC emissions are summed up at top of the graph.

age reduction and recycling of recollected $\mathrm{SF}_{6}$ from end-oflife switchgears, (b) use of $\mathrm{SO}_{2}$ as an alternative to $\mathrm{SF}_{6}$ in magnesium production and casting, and (c) phase-out of $\mathrm{SF}_{6}$ for several applications (i.e., soundproof windows). A list of $\mathrm{SF}_{6}$ control options considered in GAINS is presented in Table S7 of the Supplement together with references to literature. The removal efficiency of good practices in HMVES is assumed to be $84 \%$ (Tohka, 2005), whereas use of $\mathrm{SO}_{2}$ as an alternative to $\mathrm{SF}_{6}$ in magnesium production and casting is assumed to completely remove $\mathrm{SF}_{6}$.

In the near-term, abatement opportunities within refrigeration and air conditioning are partially restricted because many of the abatement options identified apply only to newly manufactured equipment and are thus limited by the turnover rate of the existing refrigeration and air-conditioning stock. Unless already regulated in the baseline and therefore already adopted to a large extent, the general assumption in the MFR scenario is that developed countries (i.e., non-Article 5 countries under the MP) can replace at least $75 \%$ of its use of HFCs in refrigeration and air-conditioning equipment by 2025 and $100 \%$ from 2030 onwards. For developing countries (i.e., Article 5 countries under the MP) the corresponding assumptions are $25 \%$ in $2020,50 \%$ in 2025 , and $100 \%$ from 2030 onwards. For the use of HFCs in aerosols, a general additional limit on applicability of alternative substances is set to $60 \%$ (UNFCCC, 2012), reflecting the difficulties with replacing HFC-134a and HFC-227ea in medical dose inhalers for all patient groups as no other compounds are proven to meet the stringent medical criteria required (IPCC/TEAP, 2005; USEPA, 2016).

\subsection{Politically feasible reduction scenarios}

The baseline and the MFR scenarios define the upper and lower technical boundaries for the estimated development in future F-gas emissions, with MFR defining the lowest technically feasible emission level achievable without regarding cost limitations due to financial constraints. Depending on the availability of funds and the relative importance given by policy-makers to the mitigation of climate change in comparison to other policy-relevant needs, the politically feasible emission scenario is defined by the lowest emission level attainable given a politically acceptable marginal abatement cost level. The latter is usually expressed in terms of a politically acceptable carbon price level. Within the technical boundaries defined by the baseline and MFR scenarios, we therefore develop alternative scenarios defining the expected development in future F-gas emissions when the marginal abatement cost does not exceed $0,5,10,15,20,40,60,80$, 100 and $200 \mathrm{EUR} \mathrm{t}^{-1} \mathrm{CO}_{2}$ eq. 


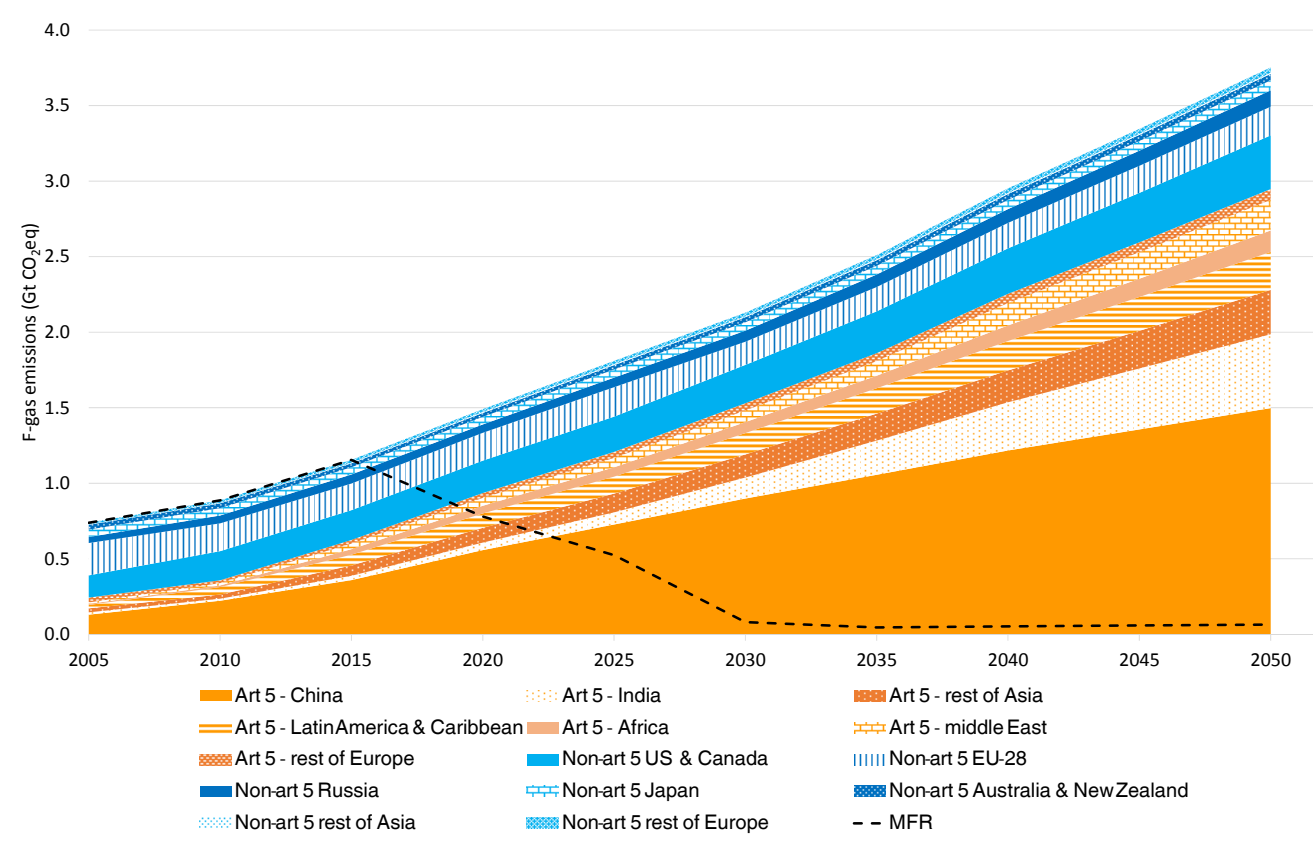

Figure 3. Baseline F-gas (HFCs, PFCs, and $\mathrm{SF}_{6}$ ) emissions by major World regions.

\section{Results}

\subsection{Baseline F-gas emissions 2005 to 2050}

Baseline F-gas emissions for the period 2005 to 2050 are presented in Fig. 2. For historical years 2005 and 2010, the contribution from F-gas (HFCs, $\mathrm{PFCs}$, and $\mathrm{SF}_{6}$ ) emissions to global warming are estimated at 0.7 and $0.89 \mathrm{Pg} \mathrm{CO}_{2}$ eq., respectively, with an additional 0.28 and $0.26 \mathrm{Pg} \mathrm{CO}_{2}$ eq. release of HCFCs in the respective years. In 2010, $34.6 \%$ of Fgas emissions are released as HFCs from stationary air conditioning and refrigeration, $13.6 \%$ as HFC-134a from mobile air conditioners, $18.6 \%$ as HFC-23 emissions from HCFC22 production for emissive and feedstock use, $7.7 \%$ as HFCs from use in aerosols, foams, solvents, fire-extinguishers, ground-source heat pumps, $12.9 \%$ as $\mathrm{SF}_{6}$ from high- and mid-voltage switches, magnesium production, soundproof windows, and other minor sources, and $12.5 \%$ as PFCs from primary aluminium production and the semiconductor industry.

Baseline F-gas emissions are estimated to increase by a factor of 5 between 2005 and 2050, as shown in Fig. 2. The growth is mainly driven by a six-fold increase in demand for refrigeration and air-conditioning services, which in turn is driven by an expected increase in per capita wealth in developing countries combined with the effect of replacing CFCs and HCFCs with HFCs in accordance with the revised MP. Under the MP, HCFCs in emissive use should be virtually phased out by 2030, but still allowing for servicing of the existing stock until 2040. HFC-23 emissions from HCFC22 production for feedstock use in industry is expected to grow significantly in China following expected growth in industry value added.

Between 2005 and 2050, PFC emissions are expected to grow by $25 \%$, which is a combination of expected growth in industry value added and emission contractions following expected switches from outdated HSS, VSS, or prebake technologies to more efficient point feed prebake (PFPB) technology in primary aluminium production. $\mathrm{SF}_{6}$ emissions are expected to increase by almost $50 \%$ over the same period due to expected growth in emissions from high- and mid-voltage switches as electricity consumption increases and due to expected growth in magnesium production, which is dominated by China (USGS, 2013b) and without adoption of control expected in the baseline.

As shown in Fig. 3, rapid growth in emissions is expected in Article 5 (developing) countries. With approximately seven-fold increases from 2010 to 2050 , China is expected to contribute $39 \%$ of global F-gas emissions in 2050 followed by India (13\%). For EU-28, F-gas emissions in 2050 will be lower than the 2005 level due to stringent Fgas controls, whereas in the USA and Canada emissions are expected to increase by a factor of 2 in the baseline scenario.

\subsection{The future technical abatement potential}

Figure 4 shows that there are extensive opportunities to reduce F-gas emissions through existing technologies or by replacement with low-GWP alternative substances. In the near-term, abatement opportunities within refrigeration and air conditioning are limited by the turnover rate of the existing refrigeration and air-conditioning stock (see Sect. 3.2). 


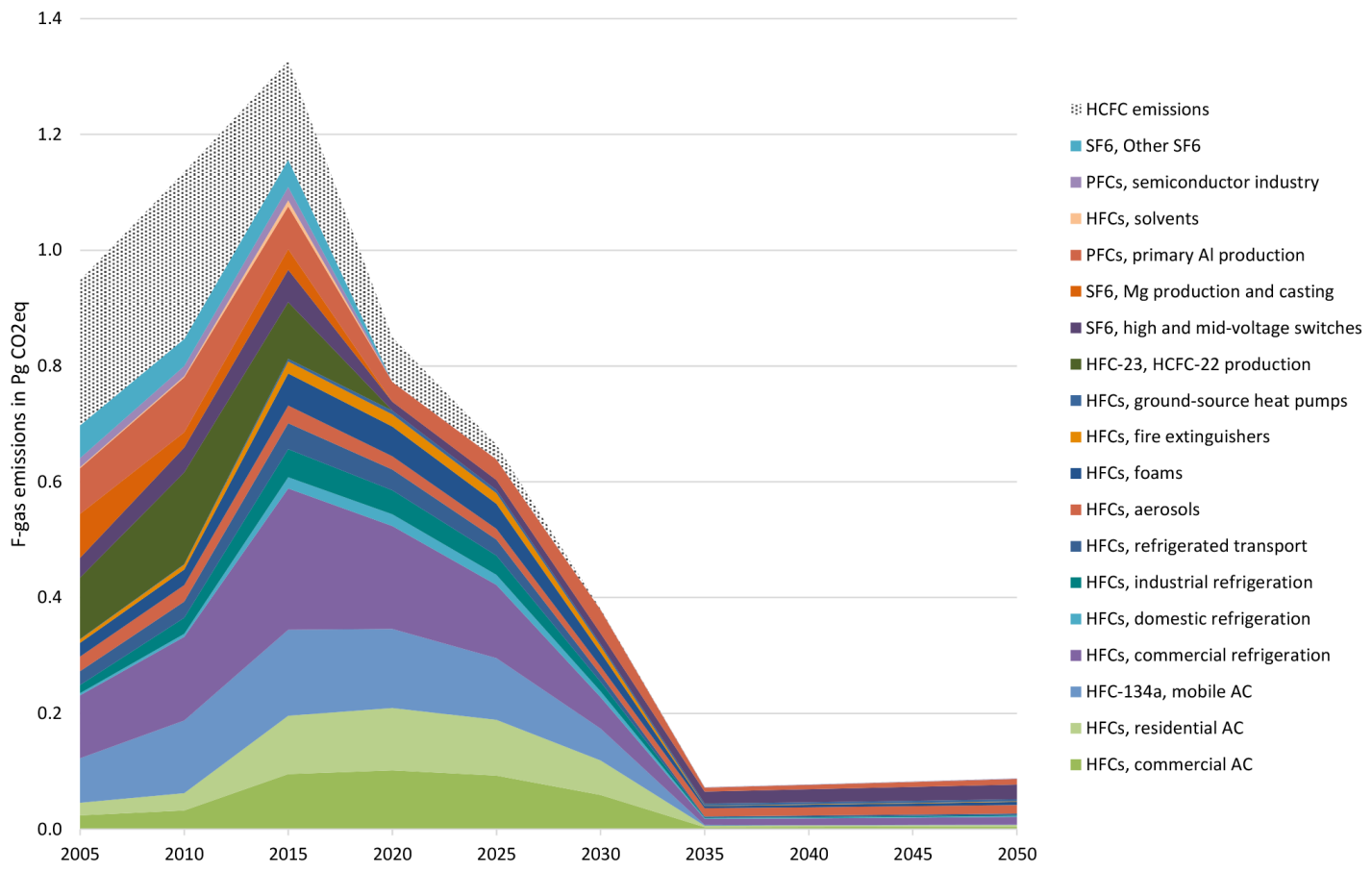

Figure 4. F-gas emissions in MFR scenario, i.e., after maximum technically feasible reduction 2020 to 2050.

The full technical abatement potential is therefore expected to be attainable from 2035 onwards and then estimated at $97 \%$ below baseline emissions, which reflects the deep cuts in emissions found to be technically feasible across all source sectors, as shown in Fig. 4.

\subsection{The cost of future technical abatement potentials}

Figure 5 shows the estimated marginal abatement cost curves for global F-gas emissions in 2020, 2030, 2040, and 2050 between the baseline and the MFR emission scenarios. The mitigation potential is extended over time, primarily due to the expected increase in baseline emissions and to a lesser extent by short-run technical limitations, to fully phase in the available abatement options. Net savings on abatement costs are primarily expected from replacement of the use of HFCs with $\mathrm{NH}_{3}$ in industrial refrigeration, switching from high to low HFCs (e.g., HFC-152a) in foam blowing, switching from the use of HFCs to hydrocarbons (e.g., propane or butane) in residential air conditioning, and switching from HFCs to $\mathrm{CO}_{2}$-based systems in transport refrigeration. The lower part of Fig. 6 shows that global annual cost savings from these options are estimated at over EUR 15 billion in 2050. The upper part of Fig. 6 shows the estimated total annual cost of implementing costly F-gas abatement options below a marginal cost of $200 \mathrm{EUR} \mathrm{t}^{-1} \mathrm{CO}_{2}$ eq. (which corresponds to $98 \%$ of the MFR abatement potential). The highest cost is attributed to the replacement of HFC-134a in cars with HFO-1234yf. The annual cost of implementing this option globally is esti- mated at almost EUR 35 billion in 2050. Replacing the HFC134a use in other types of vehicles is estimated to add EUR 8 billion annually in 2050. The total annual cost of implementing all other costly options are estimated at EUR 14 billion in 2050. Hence, global implementation of all options in 2050 (thereby achieving $98 \%$ of MFR) is estimated at a net annual cost of EUR 41 billion, of which costly options make up 57 billion and cost-saving options EUR 16 billion per year.

Figure 7 shows the estimated development in future Fgas emissions in the baseline and MFR scenarios at different carbon price levels (i.e., maximum marginal abatement cost levels). According to these estimates, a moderate carbon price level of $10 \mathrm{EUR} \mathrm{t}^{-1} \mathrm{CO}_{2}$ eq. would provide enough incentives to achieve significant emission reductions of $80 \%$ below the baseline in 2035. However, without allowing for a further increase in the carbon price in the long run, a continued increase in demand for F-gas services is expected to result in a $36 \%$ increase in global F-gas emissions between 2035 and 2050.

\subsection{Cumulative F-gas emissions and costs 2018 to 2050}

To display the effect on emissions from different climate policy ambition levels, we sum up the expected cumulative emissions released over the period 2018 to 2050 for alternative carbon price levels. By setting a positive carbon price, all abatement options that come at a marginal abatement cost lower than the carbon price can be expected to be implemented as they will render a saving to the user compared 


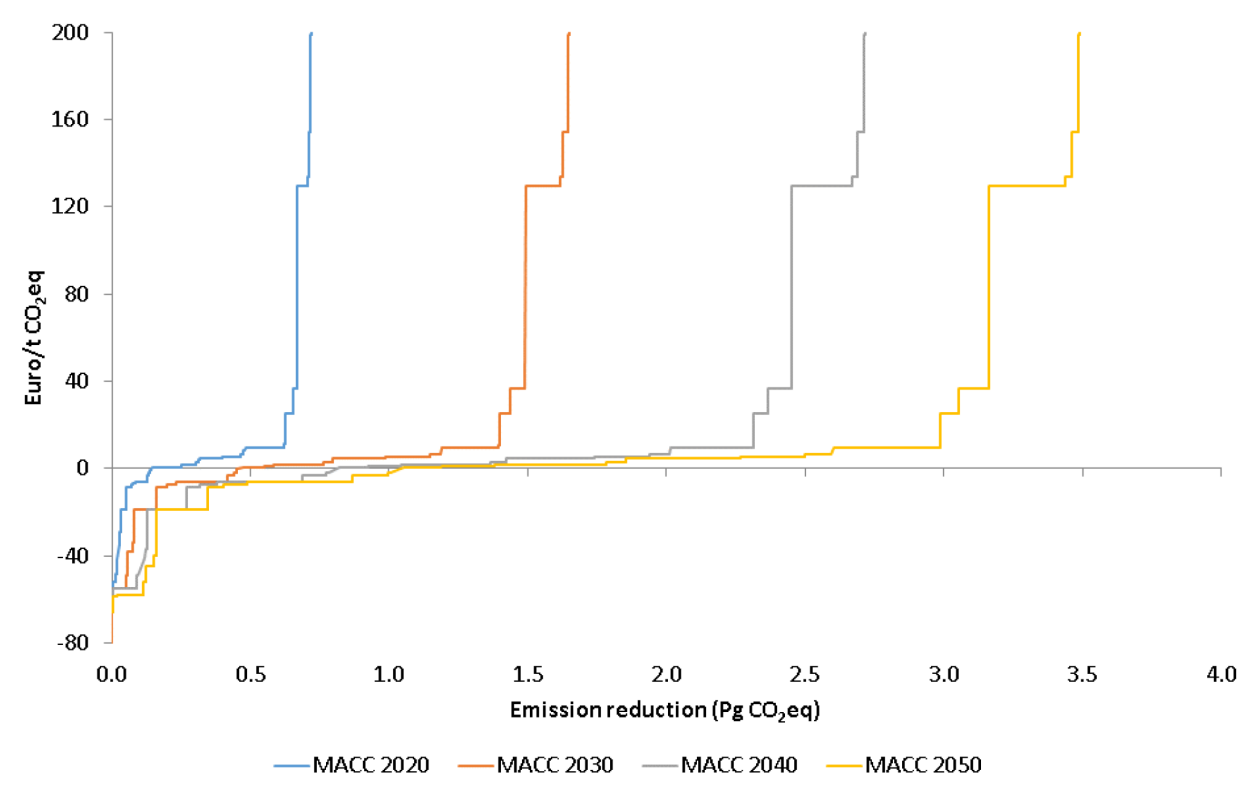

Figure 5. Marginal abatement cost curves in 2020, 2030, 2040 and 2050 for reducing global emissions of F-gases.

with paying the carbon price. We measure the cumulative emissions starting from 2018 as this is considered the earliest year from which new climate policy can realistically be in place. Figure 8 shows the estimated cumulative emissions 2018 to 2050 at different carbon price levels and for Article 5 (developing) countries and non-Article 5 (developed) countries separately. As shown, in the baseline, Article 5 countries can be expected to release $62 \mathrm{Pg} \mathrm{CO}_{2}$ eq. of F-gases, while the expected contribution from non-Article 5 countries is $19 \mathrm{PgCO}_{2}$ eq. over the entire period. With climate policies implemented globally and corresponding in stringency to a carbon price of $10 \mathrm{EUR} \mathrm{t}^{-1} \mathrm{CO}_{2}$ eq., the cumulative release over the entire period is estimated at $17 \mathrm{PgCO}_{2}$ eq. from $\mathrm{Ar}-$ ticle 5 countries and $6 \mathrm{Pg} \mathrm{CO}_{2}$ eq. from non-Article 5 countries. Globally, this means a reduction in cumulative F-gas emissions from 81 to $23 \mathrm{PgCO}_{2}$ eq. over the period 2018 to 2050 , i.e., a reduction in global cumulative emissions by $72 \%$.

Figure 9 shows the estimated total cost of achieving the cumulative emission reductions shown in Fig. 8. Non-Article 5 (i.e., primarily developed) countries have considerable opportunities to reduce emissions through options that render cost-savings. These include a switch from current use of HFCs to less-expensive alternative low-GWP substances in industrial refrigeration, foam blowing, residential air conditioning, and refrigerated transport, and relatively limited release of F-gases from mobile air conditioning and industrial processes. The cumulative net cost of abatement over the period 2018 to 2050 therefore only turns positive at a carbon price exceeding $100 \mathrm{EUR}^{-1} \mathrm{CO}_{2}$ eq. For developing countries, with a relatively limited contribution of emissions from industrial refrigeration and relatively large emissions from industrial processes and mobile air conditioning, the net cumulative abatement cost is higher and already turns positive at a carbon price of $40 \mathrm{EUR} \mathrm{t}^{-1} \mathrm{CO}_{2} \mathrm{eq}$.

\subsection{Comparison to other studies}

Figure 10 shows a comparison between our baseline estimate of global F-gas emissions 2005 to 2050 and businessas-usual scenarios of other studies. Our findings confirm previous findings (EDGAR, 2013; Gschrey et al., 2011; Meinshausen et al., 2011; Velders et al., 2009, 2014, 2015) that in 2005, emissions of HFCs, PFCs, and $\mathrm{SF}_{6}$ contributed about $0.7 \mathrm{Pg} \mathrm{CO}_{2}$ eq. to global greenhouse gas emissions. IPCC/TEAP (2005) projected F-gas emissions at a sectoral level until 2015. The projections are based on sectoral data on banked and emitted emissions in 2005 as well as projections by SROC (IPCC/TEAP, 2005) and updated projections of HFC banks and emissions for the period 2005 to 2020 by TEAP (UNEP, 2009). The projection to 2015 is very close to the baseline emissions estimated in GAINS.

Our baseline projection, reaching $3.7 \mathrm{Pg} \mathrm{CO}_{2}$ eq. in 2050, is somewhat lower than the business-as-usual estimates of 4 to $5.4 \mathrm{Pg} \mathrm{CO}_{2}$ eq. in 2050 by Velders et al. (2015) and Gschrey et al. (2011), and significantly higher than in the representative concentration pathway (RCP) scenarios (IIASA, 2009). The reason for the difference in projected emissions can be sought in the use of different drivers. Just like this study uses sector-specific drivers (e.g., growth in commercial or industry value added), Gschrey et al. (2011) apply sectorspecific assumptions to drive future trends in emissions. However, where we use region-specific drivers based on macroeconomic scenarios by IEA/OECD (2012) and Capros et al. (2013), Gschrey et al. (2011) make fixed assumptions 


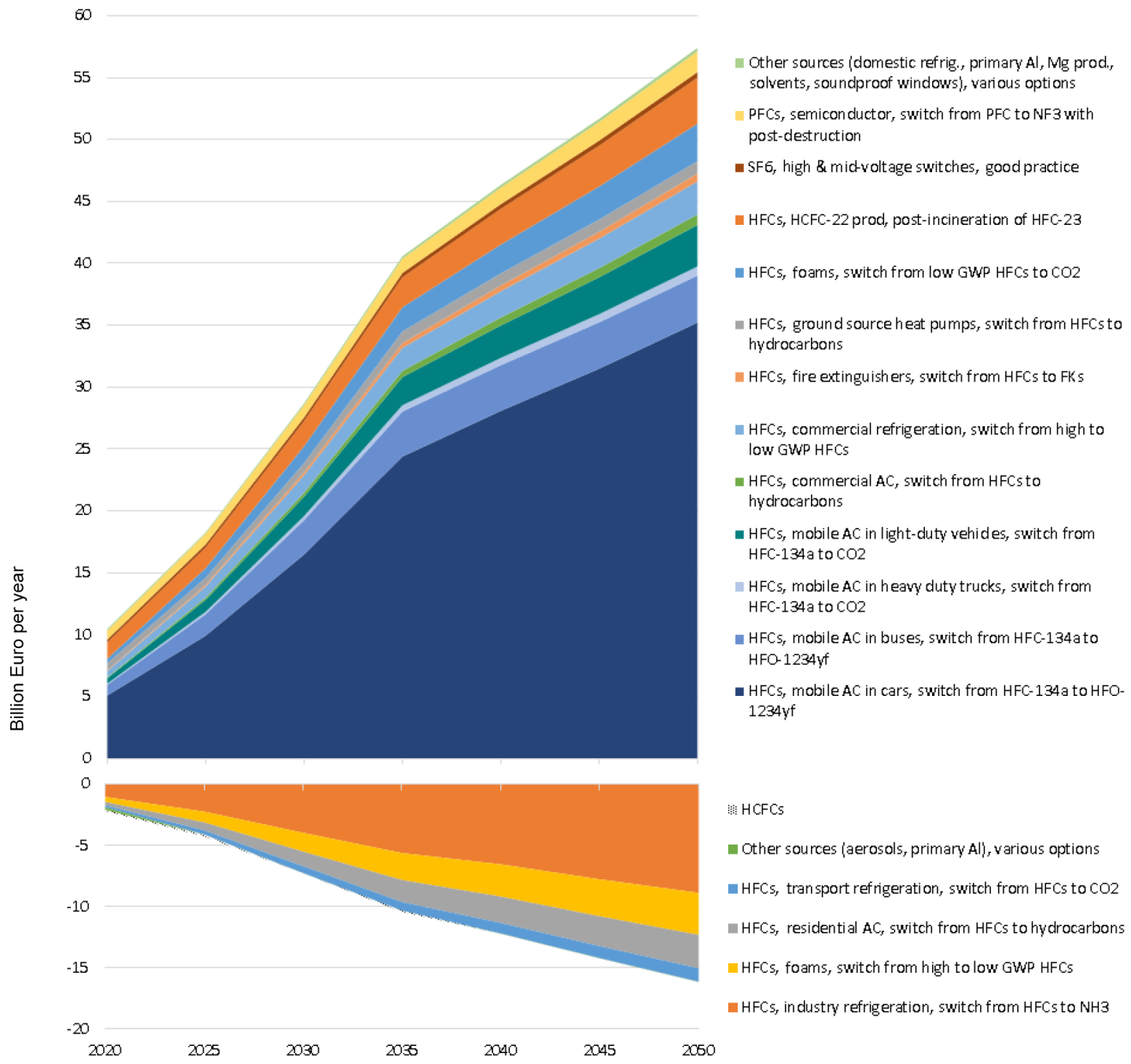

Figure 6. Total annual costs by control option for implementation of abatement options found available at a marginal cost below $200 \mathrm{EUR} / \mathrm{tCO}_{2}$ eq. (corresponding to $98 \%$ of MFR abatement potential).

for developed and developing countries, for short and longterm emission growth rates at the sectoral level, respectively. Velders et al. (2015) use GDP and population growth rates from the IPCC SSP scenarios (O'Neill et al., 2012; IIASA, 2012) as drivers for F-gas emissions. Just like Velders et al. (2015), we take account of the effects of the most recently implemented F-gas regulations, e.g., the 2014 revision of the EU F-gas regulation, and therefore differences in the level of regulation should not contribute to differences in future emissions. Our baseline, as well as the most recent business-as-usual scenario from Velders et al. (2015), project higher global F-gas emissions in 2050 than any of the different IPCC RCP scenarios (IIASA, 2009; Moss et al., 2010). In comparison to our baseline emissions in 2050 , the RCP scenarios are 59 to $88 \%$ lower. The higher projections of the more recent studies, including this one, can be explained by a strong increase in the use of F-gases with high GWPs in recent years, which are reflected in the sector-specific GWPs derived from the shares of commonly used HFCs reported by Annex-I countries to the UNFCCC (2015a). Another reason may be differences in the sector-specific GWPs used.

USEPA (2013) provides global projections of F-gases at regional and sectoral level until 2030. Their estimate for historical years is close to GAINS, but display a stronger increase in emissions between 2020 and 2030. In 2030, USEPA project global F-gas emissions at $2.6 \mathrm{Pg} \mathrm{CO}_{2}$ eq., which is $28 \%$ higher than the GAINS estimate for the same year. Apart for RCP scenarios and USEPA (2013) that provide data in 5-year intervals until 2050 and 2030, respectively, the other referenced studies provide only one point in 2020 and one in 2050 without describing the pathway between these two points. 


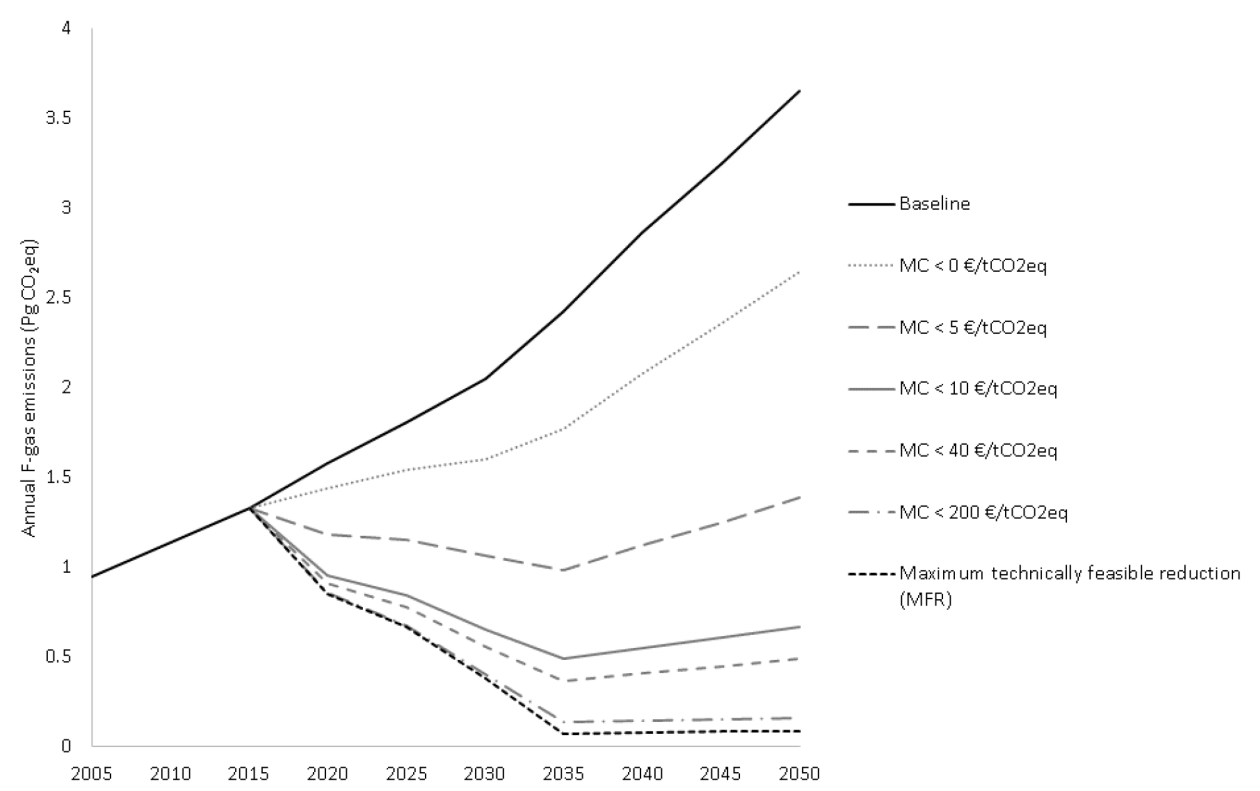

Figure 7. Estimated emission pathways for F-gas emissions at different carbon price levels.
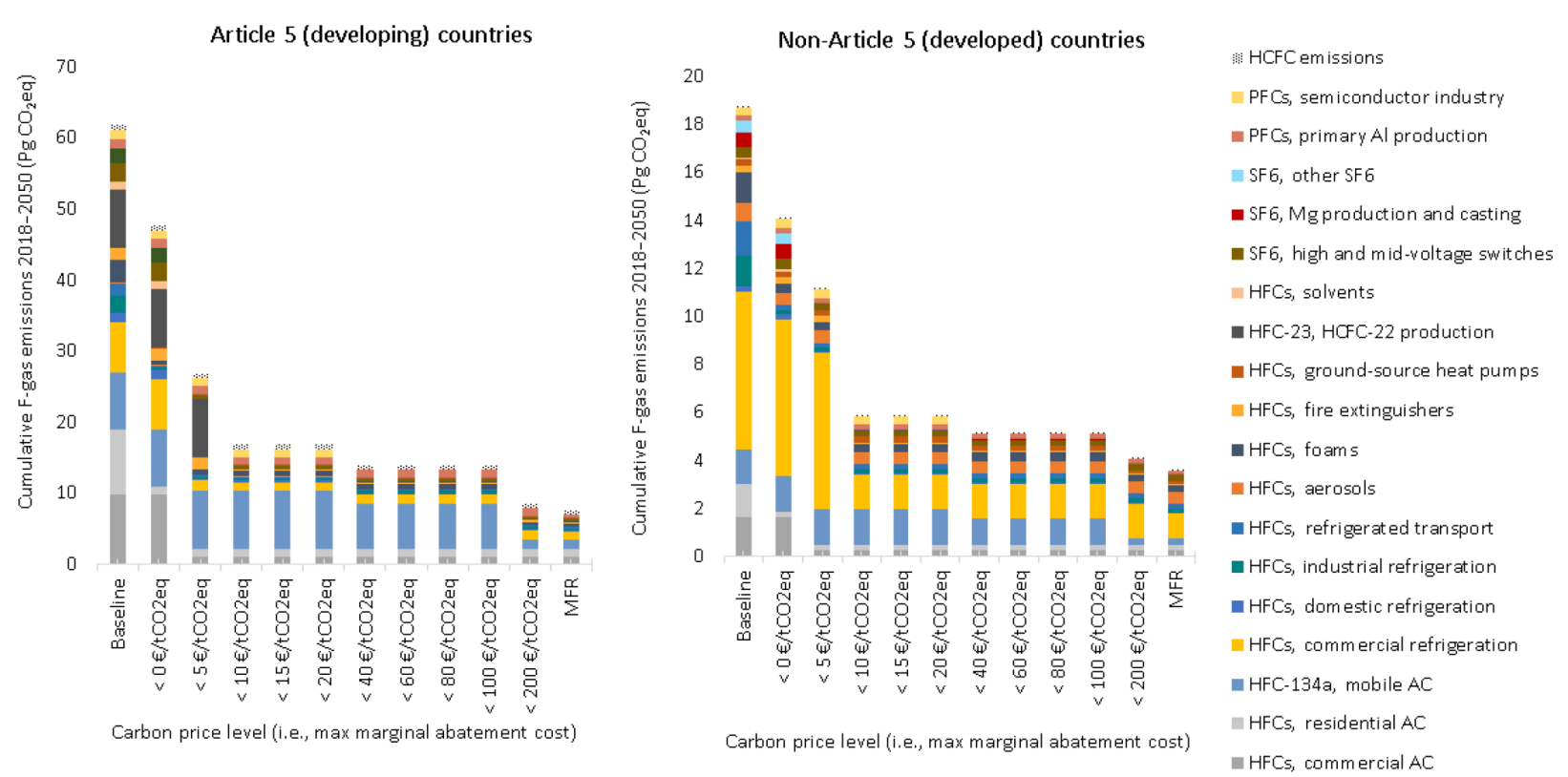

Figure 8. Estimated cumulative F-gas emissions released over the period 2018-2050 at different carbon price levels in Article 5 (developing) countries and non-Article 5 (developed) countries.

Just like Fisher et al. (2007), we find that there are significant opportunities to reduce F-gas emissions through adoption of existing alternative substances and technology.

\section{Uncertainty analysis}

It is important to acknowledge that there are several potential sources for uncertainty in the estimated emissions, abatement potentials and associated costs. This section focuses on uncertainty in the chosen methodology and information input used in the derivation of emission factors and costs. It does not address uncertainty in the projections of activity drivers as these have been taken from external sources (IEA/OECD, 2012; Capros et al., 2013). Uncertainty ranges presented in Table S10 are derived from default ranges suggested in the IPCC guidelines for National Greenhouse Gas Inventories (IPCC, 2006) and other published literature (IPCC, 2000; 

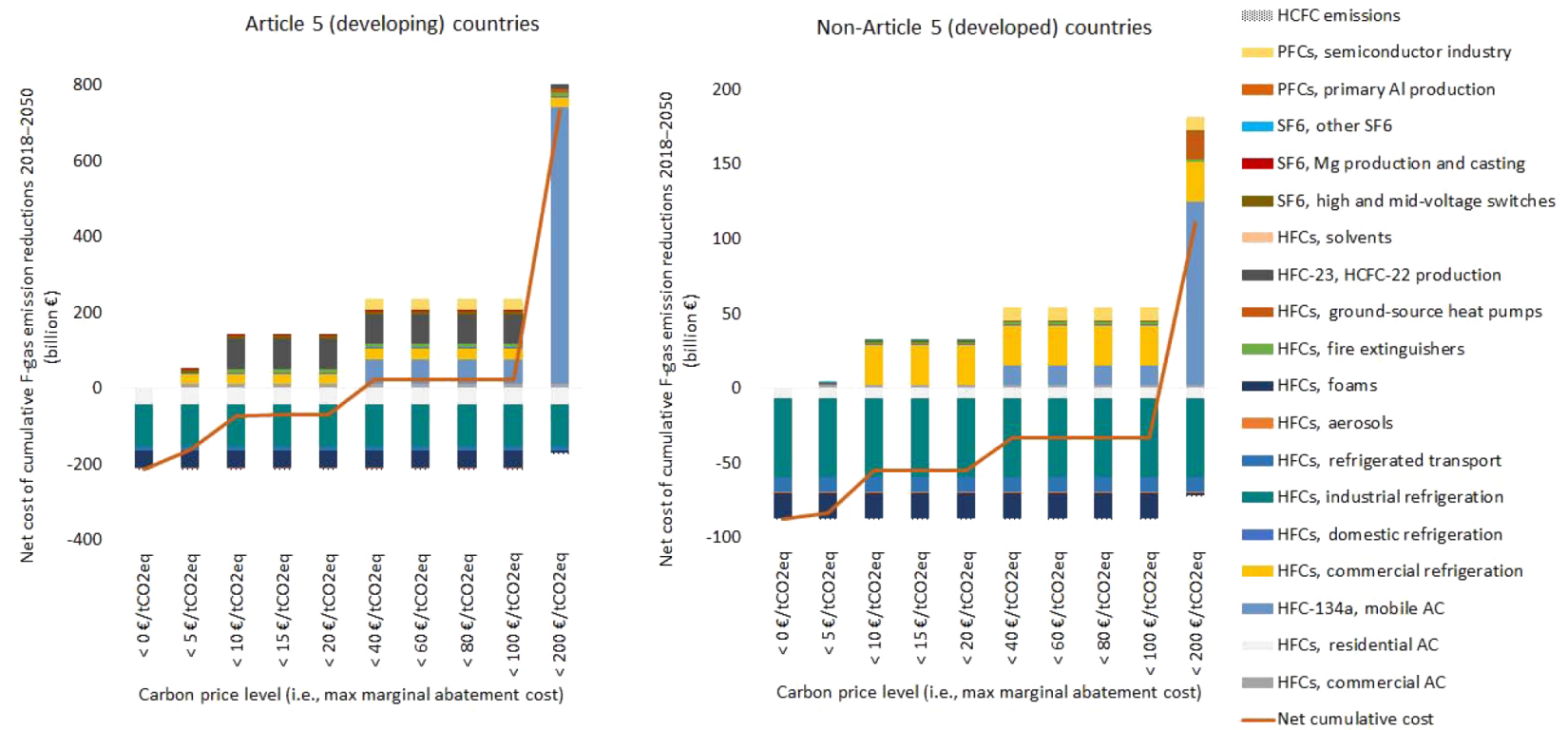

Figure 9. Net costs of cumulative reductions in F-gas emissions over the period 2018-2050 at different carbon price levels in Article 5 (developing) countries and Non-Article 5 (developed) countries.

10.0

8.0

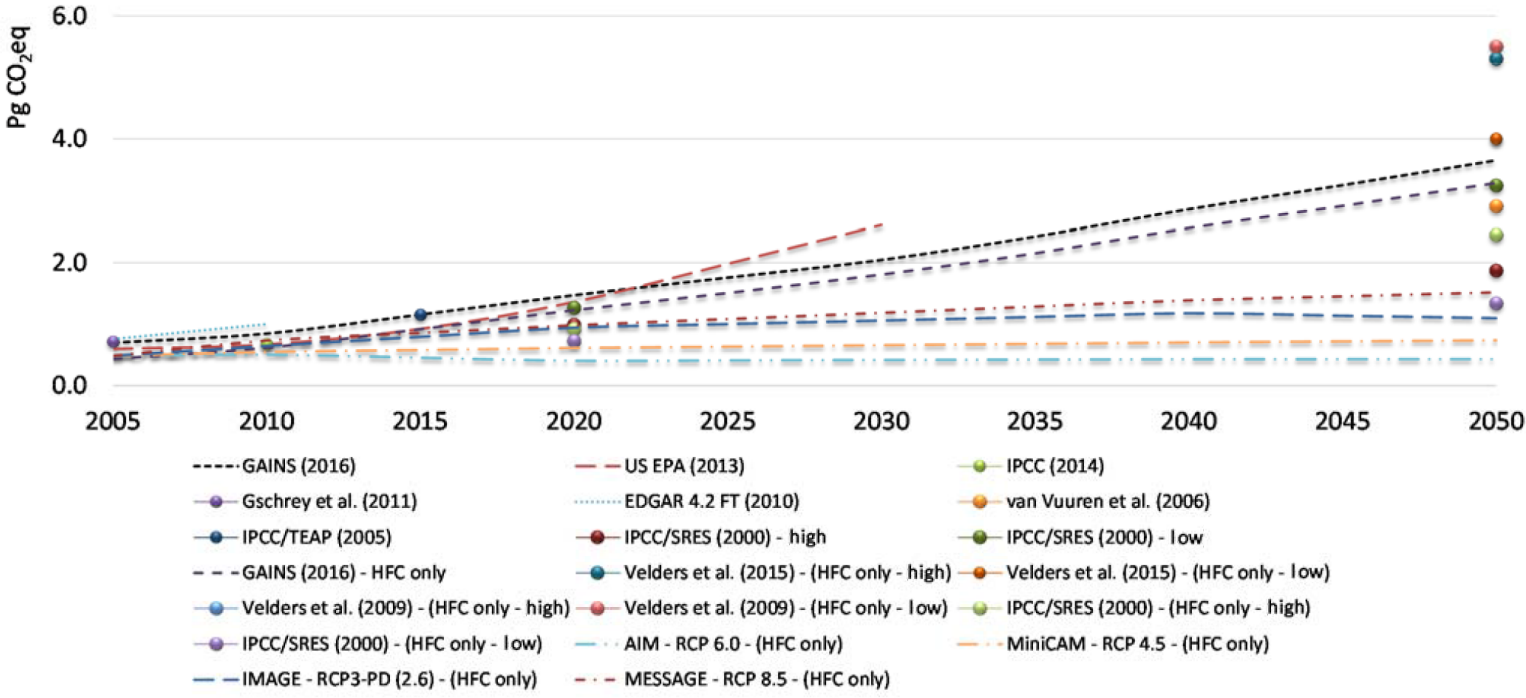

Figure 10. Comparison of GAINS baseline scenario with other F-gas business-as-usual scenarios

USEPA, 2004; UNFCCC, 2012; IPCC/TEAP, 2005; Tohka, 2005; Garg et al., 2006; Gschrey et al., 2011; Schwartz et al., 2011; McCulloch and Lindley, 2007; Koronaki et al., 2012). As mentioned in the previous section, in the baseline HFCs are expected to contribute to nearly $90 \%$ of global
F-gas emissions in 2050. Figure 11 presents ranges of uncertainty for major HFC sectors contributing $84 \%$ of global HFC emissions in 2050. Other HFC sectors (fire extinguishers, foam, solvents etc.) are not incorporated due to lack of relevant data. Moreover, we do not attempt to sum sectoral 


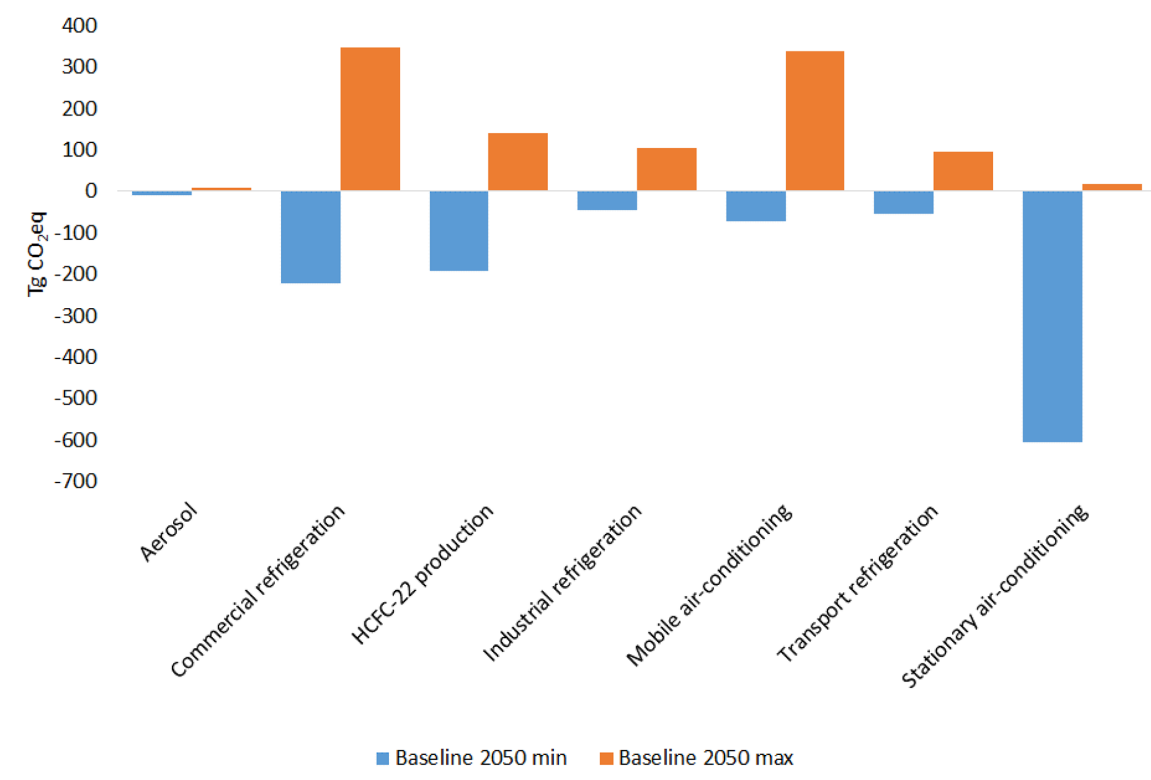

Figure 11. Uncertainty ranges by sector for global F-gas emission estimates.

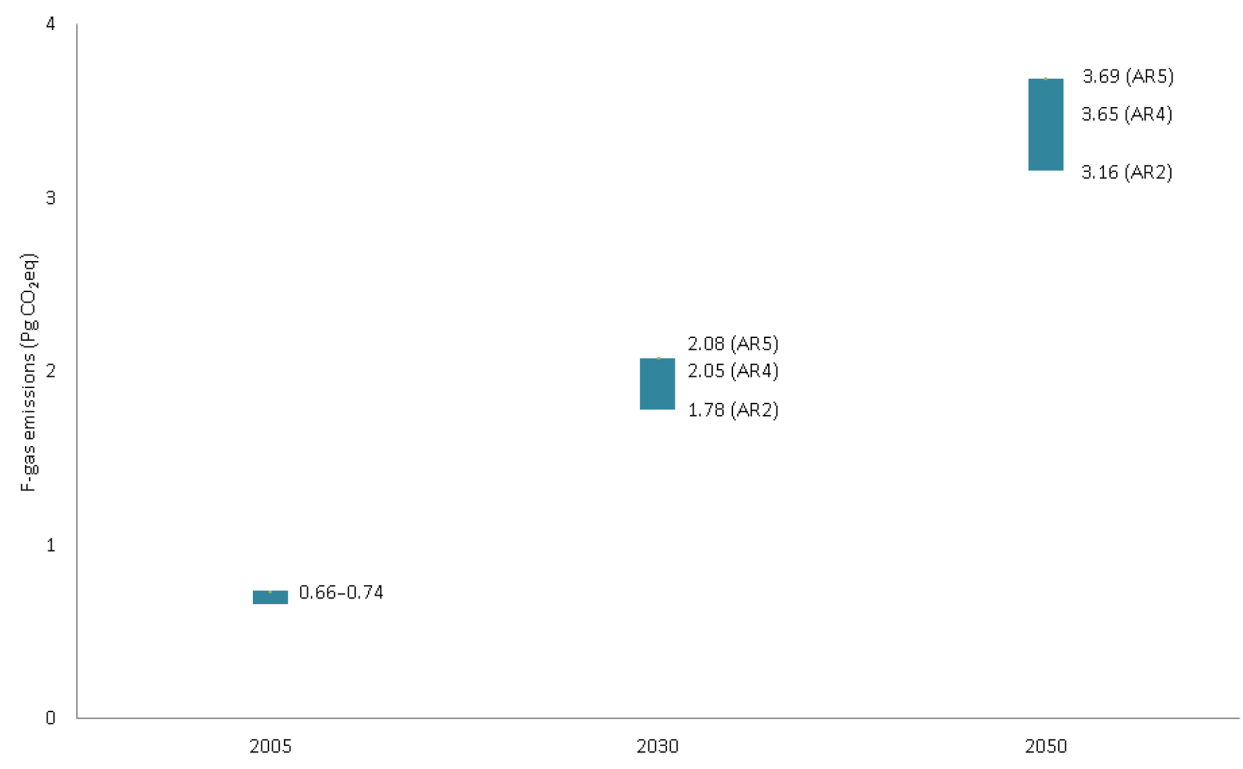

Figure 12. Global F-gas emissions using different GWPs.

uncertainty ranges at the global scale, as it is difficult to estimate relative uncertainty between sectors. Based on this data, global baseline emission estimates are most affected by uncertainty in estimates in stationary air conditioning followed by commercial refrigeration and mobile air conditioning. To reduce uncertainty in emission estimates, it would be of particular interest to obtain measurement data on sectoral emission rates of refrigerants in various world regions, to complement currently available information from Europe and North America (Schwarz and Harnisch, 2003; Schwarz, 2005; MPCA, 2012; UNFCCC, 2012). Equally important would be to improve access to measurement data which can verify reported figures, e.g., HFC-23 emissions in HCFC-22 production for major HCFC-22 producing countries.

Also note that GWP values are being continually revised to reflect current understanding of the warming potentials of $\mathrm{CO}_{2}$ relative other greenhouse gases. Figure 12 presents the impact on global F-gas emissions when using different GWPs taken from the second, fourth and fifth assessment reports of IPCC (see: Table S2). In 2050, global F-gas emissions in the baseline are estimated at $3.2 \mathrm{Pg} \mathrm{CO}_{2}$ eq. using GWPs from the Revised 1996 IPCC guidelines (IPCC, 
1997), whereas the most recent GWPs associated with climate-carbon effects (IPCC, 2014) indicate $18 \%$ higher emissions in 2050 when converted to $\mathrm{CO}_{2}$ eq. units.

Uncertainty in estimates is also affected by the quickly evolving development of alternative refrigerants and technologies in these sectors, with efficiencies in emission removal increasing and costs decreasing as research and market shares expand (USEPA, 2013). Thus, the use of current costs and removal efficiencies of existing control options is likely to render conservative estimates about the future abatement potentials and costs.

Uncertainty about the opportunities to exploit economies of scale when implementing different systems in different sectors adds to uncertainty in unit costs. For example, recovery from large equipment is more cost-effective than for small equipment, as the amount of refrigerant recoverable is greater and the relative amount of technician time needed to perform the recovery is smaller. Other sources of uncertainty affecting costs include uncertainty in estimates of the amount of refrigerant recoverable from equipment at service and disposal as it will differ by the type of equipment. Similarly, because leak repair can be performed on many different equipment types and can involve many different activities and/or tools, it is difficult to determine an average cost of such repairs or the average emission reduction associated with them. This analysis relies on broad assumptions about costs available in published literature (Tohka, 2005; Schwarz et al., 2011; Höglund-Isaksson et al., 2013; USEPA, 2013) and is not able to reflect specific local conditions affecting costs and removal efficiencies of different technologies.

\section{Conclusions}

Many fluorinated gases (F-gases) are potent greenhouse gases that contribute to global warming if released to the atmosphere. This analysis identifies and quantifies major global sources of F-gas emissions as well as technical opportunities and costs for abatement. It also pinpoints important sources of uncertainty in emission estimations, which could serve to improve future estimates. Results from the GAINS model suggest that in a baseline scenario that only takes into account effects on emissions from already adopted legislation and voluntary agreements, global emissions of F-gases are expected to grow by a factor of 5 between 2005 and 2050 (from $0.7 \mathrm{Pg} \mathrm{CO}_{2}$ eq. in 2005 to $3.7 \mathrm{Pg} \mathrm{CO}_{2}$ eq. in 2050). In particular, a sharp increase in emissions from air conditioning and refrigeration in developing countries contributes to increased emissions. We find that existing abatement technologies could reduce emissions by up to $97 \%$ below annual baseline emissions in the long run. Due to inertia in the replacement of current technology in the short run, it is considered technically feasible to reduce cumulative F-gas emissions over the entire period 2018 to 2050 by $86 \%$.
Abatement costs are found to be relatively low and, at a carbon price of $10 \mathrm{EUR}^{-1} \mathrm{CO}_{2}$ eq., incentives to adopt $\mathrm{F}$ gas abatement are expected to be strong enough to remove $72 \%$ of cumulative baseline F-gas emissions over the period 2018 to 2050 . We find that future F-gas abatement is expected to be relatively more costly for developing than for developed countries due to differences in the sector distribution of emissions. Hence, a fair and cost-effective distribution of the burden to control future global F-gases, across all sectors and regions, calls for a policy mechanism that can redistribute costs from developed to developing countries.

\section{Data availability}

Data for the scenarios presented here will be made available to the community through the global version of the GAINS model (http://gains.iiasa.ac.at/models/index.html). Requests for data should be addressed to Pallav Purohit (purohit@iiasa.ac.at).

\section{The Supplement related to this article is available online at doi:10.5194/acp-17-2795-2017-supplement.}

Competing interests. The authors declare that they have no conflict of interest.

Acknowledgements. The authors wish to acknowledge L. J. M. Kuijpers, A. McCulloch and one anonymous reviewer for valuable comments and suggestions. We would further like to acknowledge constructive comments and input from the GAINS team at IIASA.

Edited by: F. Dentener

Reviewed by: L. J. M. Kuijpers and one anonymous referee

\section{References}

AIRAH: The HFC Refrigerant Levy - The Clean Energy Future Plan and HFCs, Australian Institute of Refrigeration, Air Conditioning and Heating (AIRAH), Melbourne, 2012.

Amann, M., Kejun, J., Jiming, H., Wang, S., Wei, W., Jia, X., Chuying, Z., Bertok, I., Borken, J., Cofala, J., Heyes, C., Hoglund, L., Klimont, Z., Purohit, P., Rafaj, P., Schöpp, W., Toth, G., Wagner, F., and Winiwarter, W.: GAINS Asia: Scenarios for cost-effective control of air pollution and greenhouse gases in China, International Institute for Applied Systems Analysis (IIASA), Laxenburg, 2008 .

Amann, M., Bertok, I., Borken-Kleefeld, J., Cofala, J., Heyes, C., Höglund-Isaksson, L., Klimont, Z., Nguyen, B., Posch, M., Rafaj, P., Sandler, R., Schöpp, W., Wagner, F., and Winiwarter, W.: Cost-effective control of air quality and greenhouse gases 
in Europe: Modeling and policy applications, Environ. Modell. Softw., 26, 1489-1501, doi:10.1016/j.envsoft.2011.07.012, 2011.

Brack, D.: National Legislation on Hydrofluorocarbons, Institute for Governance \& Sustainable Development (IGSD), Washington, DC, Final draft, 11th September 2015, available at: http://igsd.org/documents/ NationalLegislationonHydrofluorocarbons_9.11.15.pdf, last access: 17 December 2016.

Capros, P., de Vita, A., Tasios, N., Papadopoulos, D., Siskos, P., Apostolaki, E., Zampara, M., Paroussos, L., Fragiadakis, K., Kouvaritakis, N., Hoglund-Isaksson, L., Winiwarter, W., Purohit, P., Bottcher, H., Frank, S., Havlík, P., Gusti, M., and Witzke, H. P.: EU Energy, Transport and GHG emissions trends to $2050-$ Reference Scenario 2013. European Commission-DirectorateGeneral for Energy, Directorate-General for Climate Action, and Directorate-General for Mobility and Transport, Publications Office of the European Union, Luxembourg, 2013.

Capros, P., de Vita, A., Tasios, N., Siskos, P., Kannavou, M., Petropoulos, A., Evangelopoulou, S., Zampara, M., Papadopoulos, D., Nakos, Ch., Paroussos, L., Fragiadakis, K., Tsani, S., Karkatsoulis, P., Fragkos, P., Kouvaritakis, N., Höglund Isaksson, L., Winiwarter, W., Purohit, P., Gomez Sanabria, A., Frank, S., Forsell, N., Gusti, M., Havlik, P., Obersteiner, M., Witzke, H. P., and Kesting, M.: EU Reference Scenario 2016: Energy, transport and GHG emissions trends to 2050, European CommissionDirectorate-General for Energy, Directorate-General for Climate Action, and Directorate-General for Mobility and Transport, Publications Office of the European Union, Luxembourg, 2016.

Carvalho, S., Andersen, S. O., Brack, D., and Sherman, N. J.: Alternatives to High-GWP Hydrofluorocarbons, Working paper, Institute for Governance and Sustainable Development (IGSD), Washington, DC, available at: http://www.igsd.org/documents/ HFCSharpeningReport.pdf (last access: 15 December 2016), 2014.

Daikin: HFC-32 - Next generation refrigerant that helps reduce global warming, Daikin Europe N.V., Brussels, available at: http://www.daikin.eu/binaries/WS_Daikin_Factsheet_ ver2.1_tcm507-401295.pdf, last access: 8 August 2016.

EDGAR: Emission Database for Global Atmospheric Research (EDGAR), 4.2 FT2010, European Commission, Joint Research Centre (JRC) and Netherlands Environmental Assessment Agency (PBL), available at: http://edgar.jrc.ec.europa.eu, last access: 22 November 2013.

EIA: The Montreal protocol in 2012 - Ending the reign of fluorocarbons, answering the call on climate. Environmental Investigation Agency (EIA), Washington, DC, 2012.

Fang, X., Hu, X., Janssens-Maenhout, G., Wu, J., Han, J., Su, S., Zhang, J. and $\mathrm{Hu}$, J.: Sulfur hexafluoride $\left(\mathrm{SF}_{6}\right)$ emission estimates for China: an inventory for 1990-2010 and a projection to 2020, Environ. Sci. Technol., 47, 3848-3855, doi:10.1021/es304348x, 2013.

Fekete, H., Roelfsema, M., Höhne, N., den Elzen, M., Forsell, N. and Becerra, S.: The impact of good practice policies on regional and global greenhouse gas emissions. New Climate Institute, PBL Netherlands Environmental Assessment Agency and International Institute for Applied Systems Analysis, Cologne, Germany, available at: https://newclimateinstitute.files.wordpress. com/2015/07/task2c_goodpracticeanalysis_july_2015.pdf, 2015.

Feng, J., Yan, H., Zhang, B., and Zhang, J.: Prediction of HFC-23 Emission and Analysis of CDM Project Impact in China, Acta Scientiarum Naturalium Universitatis Pekinensis, 48, 310-316, 2012 (in Chinese).

Fisher, B. S., Nakicenovic, N., Alfsen, K., Corfee Morlot, J., de la Chesnaye, F., Ch. Hourcade, J., Jiang, K., Kainuma, M., La Rovere, E. L., Matysek, A., Rana, A., Riahi, K., Richels, R., Rose, S., van Vuuren, D., and Warren, R.: Issues related to mitigation in the long term context, in: Climate Change 2007: Mitigation. Contribution of Working Group III to the Fourth Assessment Report of the Inter-Governmental Panel on Climate Change, edited by: Metz, B., Davidson, O. R., Bosch, P. R., Dave, R., and Meyer, L. A., Cambridge University Press, Cambridge, United Kingdom and New York, USA, 2007.

Garg, A., Shukla, P. R., and Kapshe, M.: The sectoral trends of multigas emissions inventory of India, Atmos. Environ., 40, 4608-4620, doi:10.1016/j.atmosenv.2006.03.045, 2006.

GEF: GEF Impact Evaluation of the Phase-Out of Ozone-Depleting Substances in Countries with Economies in Transition, Vol 2: Country Reports, Global Environmental Facility (GEF), Washington, D.C., 2009.

GIZ: Consumption and Emission Inventory of Fluorinated Greenhouse Gases (CFC, HCFC and HFC) in Mexico, Deutsche Gesellschaft für Internationale Zusammenarbeit (GIZ) $\mathrm{GmbH}$, Bonn, 2014.

Gschrey, B., Schwarz, W., Elsner, C., and Engelhardt, R.: High increase of global F-gas emissions until 2050, Greenhouse Gas Measurement and Management 1, 85-92, doi:10.1080/20430779.2011.579352, 2011.

Halkos, G.: Construction of abatement cost curves: The case of F-gases, Department of Economics, University of Thessaly, Greece, 2010.

Hao, H., Geng, Y., and Hang, W.: GHG emissions from primary aluminum production in China: Regional disparity and policy implications, Appl. Energ., 166, 264-272, doi:10.1016/j.apenergy.2015.05.056, 2016.

Harnisch, J. and Hendriks, C.: Economic Evaluation of Emission Reductions of HFCs, PFCs and SF6 in Europe, Ecofys, Utrecht, 2000.

Harnisch, J. and Schwarz, W.: Costs and the impact on emissions of potential regulatory framework for reducing emissions of hydrofluorocarbons, perfluorocarbons and sulphur hexafluoride, Ecofys and Öko-Recherche, Utrecht, 2003.

Harnisch, J. I., Wing, S., Jacoby, H. D., and Prinn, R. G.: Primary Aluminum Production: Climate Policy, Emissions and Costs. MIT-Joint Program on the Science and Policy of Global Change Report Series, Report No. 44 (Revised Version), 1998.

Höglund-Isaksson, L., Winiwarter, W., Purohit, P., Rafaj, P., Schöpp, W., and Klimont, Z.: EU low carbon roadmap 2050: Potentials and costs for mitigation of non- $\mathrm{CO}_{2}$ greenhouse gas emissions, Energy Strategy Reviews, 1, 97-108, doi:10.1016/j.esr.2012.05.004, 2012.

Höglund-Isaksson, L., Winiwarter, W., and Purohit, P.: Non- $\mathrm{CO}_{2}$ greenhouse gas emissions, mitigation potentials and costs in the EU-28 from 2005 to 2050: GAINS model methodology, International Institute for Applied Systems Analysis (IIASA), Laxenburg, 2013. 
Höglund Isaksson, L., Winiwarter, W., Purohit, P., and GomezSanabria, A.: Non- $\mathrm{CO}_{2}$ greenhouse gas emissions in the EU28 from 2005 to 2050: GAINS model methodology, International Institute for Applied Systems Analysis (IIASA), Laxenburg, 2016.

Huang, F.: The semiconductor industry contribution to saving energy and protecting the global environment, The Green IT International Symposium, Tokyo, 2008.

IAI: The International Aluminium Institute Report on the Aluminium Industry's Global Perfluorocarbon Gas Emissions Reduction Programme - Results of the 2008 Anode Effect Survey. International Aluminium Institute (IAI), London, 2009.

IAI: Results of the 2013 Anode Effect Survey: Report on the Aluminium Industry's Global Perfluorocarbon Gases Emissions Reduction Programme, International Aluminium Institute (IAI), London, 2014.

IEA/OECD: Energy Technology Perspective (ETP) 2010, International Energy Agency, Paris, 2010.

IEA/OECD: Energy Technology Perspectives (ETP) 2012,International Energy Agency (IEA), Paris, 2012.

IIASA: RCP Database (Representative Concentration Pathways) Version 2.0. International Institute for Applied Systems Analysis (IIASA), Laxenburg, Austria, available at: https://ntcat.iiasa. ac.at/RcpDb/dsd?Action=htmlpage $\&$ page=about (last access: 16 December 2016), 2009.

IIASA: SSP Database (Shared Socioeconomic Pathways) - Version 1.0. International Institute for Applied System Analysis (IIASA), Laxenburg, Austria 2012, available at: https://secure.iiasa.ac.at/ web-apps/ene/SspDb/dsd?Action=htmlpage $\&$ page=about $\quad$ (last access: 27 May 2016), 2012.

IPCC: Climate Change 1995: The Science of Climate Change, Intergovernmental Panel on Climate Change (IPCC), Cambridge University Press, Cambridge, UK, 1996.

IPCC: 2006 IPCC Guidelines for National Greenhouse Gas Inventories, National Greenhouse Gas Inventories Programme. Institute for Global Environmental Strategies, Hayama, Japan, 2006.

IPCC: Climate Change 2007: The Physical Science Basis. Contribution of Working Group I to the Fourth Assessment Report of the Intergovernmental Panel on Climate Change, edited by: Solomon, S., Qin, D., Manning, M., Chen, Z., Marquis, M., Averyt, K. B., Tignor, M., and Miller, H. L., Cambridge University Press, Cambridge, United Kingdom and New York, USA, 2007a.

IPCC: Climate Change 2007: Mitigation, Contribution of Working Group III to the Fourth Assessment Report of the Intergovernmental Panel on Climate Change (IPCC), edited by: Metz, B., Davidson, O. R., Bosch, P. R., and Dave, R., Meyer, L. A., Cambridge University Press, Cambridge, United Kingdom and New York, USA, 2007b.

IPCC: Climate Change 2014: Mitigation of Climate Change, Contribution of Working Group III to the Fifth Assessment Report of the Intergovernmental Panel on Climate Change (IPCC), Cambridge University Press, Cambridge, UK and New York, USA, 2014

IPCC/SRES: Special Report on Emission Scenarios (SRES) - A Special Report of Working Group III of the Intergovernmental Panel on Climate Change (IPCC), Cambridge University Press, Cambridge, UK and New York, USA, 2000.

IPCC/TEAP: IPCC/TEAP Special Report on Safeguarding the Ozone Layer and the Global Climate System: Issues Related to Hydrofluorocarbons and Perfluorocarbons. Intergovernmental Panel on Climate Change (IPCC) and Technology and Economic Assessment Panel (TEAP), Cambridge University Press, Cambridge, United Kingdom and New York, USA, available at: http:// www.ipcc.ch/pdf/special-reports/sroc/sroc_full.pdf (last access: 24 April 2014), 2005.

Kauffeld, M.: Availability of low GWP alternatives to HFCs Feasibility of an early phase-out of HFCs by 2020, Environmental Investigation Agency (EIA), Washington DC, May 2012, available at: http://www.eia-international.org/wp-content/uploads/ EIA_FGas_Report_0412_FINAL_MEDRES_v3.pdf (last access: 12 February 2015), 2012.

Koronaki, I. P., Cowan, D., Maidment, G., Beerman, K., Schreurs, M., Kaar, K., Chaer, I., Gontarz, G., Christodoulaki, R. I., and Cazauran, X.: Refrigerant emissions and leakage prevention across Europe - Results from the Real Skills Europe project, Energy, 45, 71-80, doi:10.1016/j.energy.2012.05.040, 2012.

Macias, J., Aguilar, A., Schmid, G., and Francke, E.: Policy Handbook for the Regulation of Imported Second-Hand Vehicles, Global Fuel Economy Initiative (GFEI), Mexico, June 2013, available at: https://www.globalfueleconomy.org/media/45362/ wp7_regulation_for_2nd-hand_vehicles-lr.pdf (last access: 18 December 2016), 2013.

Mahapatra, A.: India acts on HFC-23 super pollutant as Montreal Protocol negotiations enter critical phase, 13th October 2016, available at: http: //www.businesswire.com/news/home/20161013006357/en/ India-Acts-HFC-23-Super-Pollutant-Montreal-Protocol (last access: 17 December 2016), 2016.

McCulloch, A. and Lindley, A. A.: Global emissions of HFC23 estimated to year 2015, Atmos. Environ,. 41, 1560-1566, doi:10.1016/j.atmosenv.2006.02.021, 2007.

Meinshausen, M., Smith, S. J., Calvin, K., Daniel, J. S., Kainuma, M. L. T., Lamarque, J.-F., Matsumoto, K., Montzka, S., Raper S., Riahi, K., Thomson, A., Velders, G. J. M., and van Vuuren, D. P.: The RCP Greenhouse Gas Concentrations and their Extensions from 1765 to 2300, Climatic Change, 109, 213-241, doi:10.1007/s10584-011-0156-z, 2011.

METI: Act on the Rational Use and Proper Management of Fluorocarbons (Act no. 64 of 2001). Ministry of Economy, Trade and Industry (METI), Tokyo, 2015, available at: http://conf.montreal-protocol.org/meeting/workshops/hfc_ management/presentations/StatementsbyHeadsofDelegations/ 4-MasafumiOhki_session_4.ppt (last access: 7 July 2016), 2015.

Miller, B. R. and Kuijpers, L. J. M.: Projecting future HFC-23 emissions, Atmos. Chem. Phys., 11, 13259-13267, doi:10.5194/acp11-13259-2011, 2011.

Miller, B. R., Rigby, M., Kuijpers, L. J. M., Krummel, P. B., Steele, L. P., Leist, M., Fraser, P. J., McCulloch, A., Harth, C., Salameh, P., Mühle, J., Weiss, R. F., Prinn, R. G., Wang, R. H. J., O’Doherty, S., Greally, B. R., and Simmonds, P. G.: HFC$23\left(\mathrm{CHF}_{3}\right)$ emission trend response to $\mathrm{HCFC}-22\left(\mathrm{CHClF}_{2}\right)$ production and recent HFC-23 emission abatement measures, Atmos. Chem. Phys., 10, 7875-7890, doi:10.5194/acp-10-78752010, 2010.

MoEF: Roadmap for Phase-out of HCFCs in India, Ozone cell, Ministry of Environment \& Forests (MoEF), Government of India, New Delhi, 2009. 
MoEF: HCFC Phase-out Management Plan (HPMP) Stage I, Ozone Cell, Ministry of Environment and Forest (MoEF), Government of India, New Delhi, 2013.

Montzka, S. A., Kuijpers, L., Battle, M. O., Aydin, M., Verhulst, K. R., Saltzman, E. S., and Fahey, D. W.: Recent increases in global HFC-23 emissions, Geophys. Res. Lett., 37, L02808, doi:10.1029/2009GL041195, 2010.

Montzka, S. A., Dlugokencky, E. J., and Butler, J. H.: Non$\mathrm{CO}_{2}$ greenhouse gases and climate change, Nature, 476, 43-50, doi:10.1038/nature10322, 2011.

Moss, R. H., Edmonds, J. A., Hibbard, K. A., Manning, M. R., Rose, S. K., van Vuuren, D. P., Carter, T. R., Emori, S., Kainuma, M., Kram, T., Meehl, G. A., Mitchell, J. F. B., Nakicenovic, N., Riahi, K., Smith, S. J., Stouffer, R. J., Thomson, A. M., Weyant, J. P., and Wilbanks, T. J.: The next generation of scenarios for climate change research and assessment, Nature, 463, 747-756, doi:10.1038/nature08823, 2010.

MPCA: Mobile Air Conditioner Leakage Rates - Model Year 2012, Minnesota Pollution Control Agency (MPCA), Minnesota, 2012, available at: http://www.pca.state.mn.us/index. php/view-document.html?gid=14910 (last access: 14 April 2014), 2012.

Mühle, J., Ganesan, A. L., Miller, B. R., Salameh, P. K., Harth, C. M., Greally, B. R., Rigby, M., Porter, L. W., Steele, L. P., Trudinger, C. M., Krummel, P. B., O’Doherty, S., Fraser, P. J., Simmonds, P. G., Prinn, R. G., and Weiss, R. F.: Perfluorocarbons in the global atmosphere: tetrafluoromethane, hexafluoroethane, and octafluoropropane, Atmos. Chem. Phys., 10, 5145-5164, doi:10.5194/acp-10-5145-2010, 2010.

Munnings, C., Leard, B., and Bento, A.: The Net Emissions Impact of HFC-23 Offset Projects from the Clean Development Mechanism, Discussion Paper Number RFF DP 16-01, January 2016, available at: http://www.rff.org/files/document/file/ RFF-DP-16-01.pdf, last access: 15 December 2016.

NDRC: China's Policies and Actions on Climate Change 2015. The National Development and Reform Commission (NDRC) of the People's Republic of China, November 2015, available at: http://en.ccchina.gov.cn/archiver/ccchinaen/UpFile/ Files/Default/20151120095849657206.pdf, 2015.

O’Neill, B. C., Carter, T. R., Ebi, K. L., Edmonds, J., Hallegatte, S., Kemp-Benedict, E., Kriegler, E., Mearns, L., Moss, R., Riahi, K., van Ruijven, B., and van Vuuren, D.: Meeting Report of the Workshop on the Nature and Use of New Socioeconomic Pathways for Climate Change Research, National Center for Atmospheric Research (NCAR), Boulder, CO, 2-4 November 2011, Final Version, 12 March 2012, available at: http://www.isp.ucar. edu/socio-economic-Pathways, last access: 27 May 2016.

PU: HCFCs phasing-out management plan for China, College of Environmental Sciences, Peking University (PU), Beijing, 2012.

Purohit, P., Amann, M., Mathur, R., Bhandari, P., Bertok, I., Borken, J., Cofala, J., Heyes, C., Klimont, Z., Rafaj, P., Schöpp, W., Wagner, F., and Winiwarter, W.: GAINS-Asia, Scenarios for costeffective control of air pollution and greenhouse gases in India, International Institute for Applied Systems Analysis (IIASA), Laxenburg, 2010.

Purohit, P., Höglund-Isaksson, L., Bertok, I., Chaturvedi, V., and Sharma, M.: Scenario analysis for HFC emissions in India: Mitigation potential and costs, CEEW-IIASA Report, September
2016, available at: http://pure.iiasa.ac.at/13861/, last access: 16 December 2016.

Ragnauth, S. A., Creason, J., Alsalam, J., Ohrel, S., Petrusa, J. E., and Beach, R. H.: Global mitigation of non- $\mathrm{CO}_{2}$ greenhouse gases: marginal abatement costs curves and abatement potential through 2030, Journal of Integrative Environmental Sciences, 12, 155-168, doi:10.1080/1943815X.2015.1110182, 2015.

Schneider, L., Spalding-Fecher, R., and Cames, M.: Delivering Results-Based Funding Through Crediting Mechanisms: Assessment of Key Design Options, Öko-Institut e.V., November 2015, available at: https://www.oeko.de/oekodoc/2443/2015-600-en. pdf (last access: 27 April 2016), 2015.

Schneider, L. R.: Perverse incentives under the CDM: an evaluation of HFC-23 destruction projects, Clim. Policy, 11, 851-864, doi:10.3763/cpol.2010.0096, 2011.

Schwarz, W.: Emissions and Emission Projections of HFC, $\mathrm{PFC}$ and $\mathrm{SF}_{6}$ in Germany - Present State and Development of a Monitoring System Emissions 1990, 1999-2003, and Emission Forecasts for 2010 and 2020, Prepared for Nature Conservation and Nuclear Safety, Environmental Research of the Federal Ministry of the Environment, Germany, available at: http://www.oekorecherche.de/sites/default/ files/publikationen/e-projections-2010-2020.pdf (last access: 22 June 2014), 2005.

Schwarz, W. and Harnisch, J.: Final Report on Establishing the Leakage Rates of Mobile Air Conditioners, Prepared for the European Commission (DG Environment), Öko-Recherche GmbH, Germany, available at: http://ec.europa.eu/clima/policies/eccp/ docs/leakage_rates_final_report_en.pdf (last access: 27 July 2014), 2003.

Schwarz, W., Gschrey, B., Leisewitz, A., Herold, A., Gores, S., Papst, I., Usinger, J., Oppelt, D., Croiset, I., Pedersen, H., Colbourne, D., Kauffeld, M., Kaar, K., and Lindborg, A.: Preparatory study for a review of Regulation (EC) No 842/2006 on certain fluorinated greenhouse gases, Final Report Prepared for the European Commission in the context of Service Contract No 070307/2009/548866/SER/C4, European Commission, Brussels, 2011.

Tohka, A.: The GAINS Model for Greenhouse Gases - Version 1.0: HFC, PFC and SF6, International Institute for Applied Systems Analysis (IIASA), Laxenburg, 2005.

UNDP: Malaysia HCFC Phase-Out Management Plan (HPMP Stage-1) for Compliance with the 2013 AND 2015 Control Targets for Annex-C, Group-I Substances, Prepared jointly by: Malaysia Department of Environment (DOE) and United Nations Development Programme (UNDP), April 2012, available at: https://www.doe.gov.my/portalv1/wp-content/uploads/2014/ 01/Malaysia-HPMP-Book-Final-R4-1-Part1.pdf (last access: 18 December 2016), 2012.

UNDP: Study of the hydrofluorocarbons (HFCs) market in Colombia, Final report, National Ozone Unit of Colombia, Ministry of Environment and Sustainable Development and United Nations Development Programme (UNDP), Bogotá, 2014a.

UNDP: Survey of the hydrofluorocarbon (HFC) market in Chile, Final Report, Ministry of Environment and United Nations Development Programme (UNDP), Santiago, 2014b.

UNEP: Report of the task force on HCFC issues and emissions reduction benefits arising from earlier HCFC phase-out and other 
practical measures, United Nations Environment Programme (UNEP), Nairobi, 2007

UNEP: Report of the Technology and Economic Assessment Panel (TEAP) - Task Force Decision XX/8 Report: Assessment of Alternatives to HCFCs and HFCs and Update of the TEAP 2005 Supplement Report Data, United Nations Environment Programme (UNEP), Nairobi, 2009.

UNEP: Executive committee of the multilateral fund for the implementation of the Montreal protocol. United Nations Environment Programme (UNEP), Sixty-fourth Meeting Montreal, 25-29 July 2011a.

UNEP: Latin America and the Caribbean -Passenger vehicle standards and fleets, United Nations Environment Programme (UNEP), August, available at: http://www.unep.org/transport/pcfv/PDF/Maps_Matrices/ LAC/matrix/LAC_vehiclestandardsmatrix_august2011.pdf (last access: 17 December 2016), 2011 b.

UNEP: Turkey to strengthen legislation on ozone-depletion and fluorinated gases, United Nations Environment Programme (UNEP), Nairobi, 2013.

UNEP: Additional Information to Alternatives on ODSs, Decision XXV/5, Task Force Report, Technology and Economic Assessment Panel, United Nations Environment Programme, Nairobi, 2014a.

UNEP: Desk Study on the Evaluation of HCFC Phase-Out Projects in the Foam Sector, Executive Committee of the Multilateral Fund for the Implementation of the Montreal Protocol, Seventythird Meeting, Paris, 9-13 November 2014b.

UNEP: Ozone Secretariat - Data Access Centre, United Nations Environment Programme (UNEP), Nairobi, available at: http://ozone.unep.org/en/data-reporting/data-centre (last access: 5 November 2014), 2014c.

UNEP: Open-ended Working Group of the Parties to the Montreal Protocol on Substances that Deplete the Ozone Layer (UNEP/OzL.Pro.WG.1/34/INF/4/Add.1). United Nations Environment Programme (UNEP, 34th meeting, Paris, 14-18 July 2014d.

UNEP: Safe use of HCFC alternatives in refrigeration and air-conditioning: An overview for developing countries, Ozon Action Programme, Division of Technology, Industry \& Economics, United Nations Environment Programme (UNEP), Paris, available at: http://www.unep.org/ozonaction/Portals/105/documents/7740e-SafeUseofHCFCAlternativesinRefrigerationandAirconditioning.pdf (last access: 12 December 2016), 2015.

UNEP: Lower-GWP Alternatives in Commercial and Transport Refrigeration: An expanded compilation of propane, $\mathrm{CO}_{2}$, ammonia and HFO case studies, United Nations Environment Programme (UNEP), Nairobi, available at: http://www.unep.org/ozonaction/Portals/105/Publications/ CCAC_case_studies_2016_final.pdf, last access: 15 December 2016a.

UNEP: Decision XXVIII/Further Amendment of the Montreal Protocol, Twenty-Eighth Meeting of the Parties to the Montreal Protocol om Substances that Deplete the Ozone Layer, UNEP/OzL.Pro.28/CRP/11, 14 October 2016, United Nations Environment Programme (UNEP), Nairobi, 2016b.

UNEP \& SEPA: Alternatives to HCFCs in the Refrigeration and Air conditioning Sector: Practical Guidelines and Case Studies for
Equipment Retrofit and Replacement, Ozone Action Programme, Division of Technology, Industry \& Economics, United Nations Environment Programme (UNEP) and Swedish Environmental Protection Agency (SEPA), Paris, available at: http://www.unep. org/pdf/hcfc-alternatives.pdf (last access: 14 December 2016), 2010 .

UNFCCC: Common Reporting Format (CRF) Tables and National Inventory Reports (NIRs), United Nations Framework Convention on Climate Change (UNFCCC), Bonn, 2012.

UNFCCC: National Inventory Submissions 2014 to the United Nations Framework Convention of Climate Change (UNFCCC), Climate Change Secretariat, Bonn, available at: http://unfccc.int (last access: 22 December 2015), 2014.

UNFCCC: Common Reporting Format (CRF) Tables and National Inventory Reports (NIRs), United Nations Framework Convention on Climate Change (UNFCCC), Bonn, 2015a.

UNFCCC: INDCs as communicated by Parties, United Nations Framework Convention on Climate Change (UNFCCC), Bonn, available at: http://www4.unfccc.int/submissions/indc/ SubmissionPages/submissions.aspx (last access: 17 December 2016), $2015 b$.

UNFCCC: Adoption of the Paris Agreement, Report No. FCCC/CP/2015/L.9/Rev.1, United Nations Framework Convention on Climate Change (UNFCCC), Bonn, available at: http: //unfccc.int/resource/docs/2015/cop21/eng/109r01.pdf (last access: 17 December 2016), 2015c.

USEPA: Global Emissions Report for Non- $\mathrm{CO}_{2}$ Gases - Preliminary Report, United States Environmental Protection Agency (USEPA), June 2004

USEPA: Global Anthropogenic Non- $\mathrm{CO}_{2}$ Greenhouse Gas Emissions: 1990 - 2020, Office of Atmospheric Programs Climate Change Division, U.S. Environmental Protection Agency (EPA), Washington D.C., 2006.

USEPA: EPA and NHTSA Set Standards to Reduce Greenhouse Gases and Improve Fuel Economy for Model Years 2017-2025 Cars and Light Trucks. United States Environmental Protection Agency (USEPA), Office of Transportation and Air Quality, EPA-420-F-12-051, Washington, D.C., available at: https:// www3.epa.gov/otaq/climate/documents/420f12051.pdf (last access: 28 October 2015), 2012.

USEPA: Global Mitigation of Non- $\mathrm{CO}_{2}$ Greenhouse Gases: 2010 2030 (No. EPA-430-R-13-011), United States Environmental Protection Agency (USEPA), Washington, D.C., September 2013.

USEPA: Protection of Stratospheric Ozone: Change of Listing Status for Certain Substitutes under the Significant New Alternatives Policy Program, EPA-HQ-OAR-2014-0198, United States Environmental Protection Agency (USEPA), Washington, D.C., 2015.

USEPA: Substitutes in Aerosol Propellants. Significant New Alternatives Policy Program, United States Environmental Protection Agency (USEPA), Washington, D.C., available at: https: //www.epa.gov/snap/substitutes-aerosol-propellants (last access: 1 July 2016), 2016.

USGS: Aluminum Statistics and Information, Mineral Resources Program, United States Geological Survey (USGS), Virginia, available at: http://minerals.usgs.gov/minerals/pubs/commodity/ aluminum/ (last access: 27 May 2015), 2013a. 
USGS: Magnesium Statistics and Information, Mineral Resources Program, United States Geological Survey (USGS), Virginia, available at: http://minerals.usgs.gov/minerals/pubs/commodity/ magnesium/ (last access: 27 May 2015), 2013b.

USGS: World Smelter Production and Capacity, Mineral Resources Program, United States Geological Survey (USGS), Virginia, available at: http://minerals.usgs.gov/minerals/pubs/commodity/ aluminum/mcs-2016-alumi.pdf, last access: 7 July 2016.

Velders, G. J. M., Fahey, D. W., Daniel, J. S., McFarland, M., and Andersen, S. O.: The large contribution of projected HFC emissions to future climate forcing, P. Natl. Acad. Sci. USA, 106, 10949-10954, doi:10.1073/pnas.0902817106, 2009.

Velders, G. J. M., Solomon, S., and Daniel, J. S.: Growth of climate change commitments from HFC banks and emissions, Atmos. Chem. Phys., 14, 4563-4572, doi:10.5194/acp-14-45632014, 2014.

Velders, G. J. M., Fahey, D. W., Daniel, J. S., Andersen, S. O., and McFarland, M.: Future atmospheric abundances and climate forcings from scenarios of global and regional hydrofluorocarbon (HFC) emissions, Atmos. Environ., 123, 200-209, doi:10.1016/j.atmosenv.2015.10.071, 2015.

Wara, M.: Is the global carbon market working?, Nature, 445, 595596, doi:10.1038/445595a, 2007.
World Bank: Study on financing the destruction of unwanted ozonedepleting substances through the voluntary carbon market, Montreal Protocol Unit, Washington D.C., February 2010.

WSC: Joint Statement of the 20th Meeting of World Semiconductor Council (WSC), Seoul, 26 May 2016, available at: http://www.semiconductorcouncil.org/wp-content/uploads/ 2016/04/2016-WSC-Joint-Statement-with-Annexes.pdf, last access: 5 July 2016.

Yong, W.: Introduction of China HCFCs Phase-out Management Plan. ATMOsphere Technology Summit, Vienna, 3-4 June 2013, available at: www.atmo.org/presentations/files/213 2_FECO_Yong.pdf (last access: 15 December 2016), 2013.

Zaelke, D. and Borgford-Parnell, N.: The importance of phasing down hydrofluorocarbons and other short-lived climate pollutants, Journal of Environmental Studies and Sciences, 5, 169175, doi:10.1007/s13412-014-0215-7, 2015. 